Journal of Advanced Research in Fluid Mechanics and Thermal Sciences

Journal homepage: www.akademiabaru.com/arfmts.html ISSN: 2289-7879

\title{
MHD Natural Convection in a Fully Opened Parallelogrammic Enclosure Filled with Copper-Water Nanofluid and Partially Heated from its Left Sidewall
}

\author{
Ihsan Ali Ghani ${ }^{1,}{ }^{*}$, Farhan A. Khammas ${ }^{2}$, Ahmed Waheed Mustafa ${ }^{2}$, Ahmed Kadhim Hussein $^{3}$ \\ College of Engineering, Mechanical Engineering Department, Al-Mustansiriyah University, Baghdad City, Iraq \\ College of Engineering, Mechanical Engineering Department, Al-Nahrain University, Baghdad City, Iraq \\ College of Engineering, Mechanical Engineering Department, University of Babylon, Babylon City, Hilla, Iraq
}

\section{ARTICLE INFO}

\section{Article history:}

Received 20 January 2020

Received in revised form 11 May 2020

Accepted 21 May 2020

Available online 15 August 2020

\section{Keywords:}

MHD, Natural convection; Nanofluid;

Partial heating; Parallelogrammic

enclosure

\section{ABSTRACT}

The present work examined numerically for the first time, the magneto-hydrodynamics (MHD) natural convection flow and heat transfer in a fully opened parallelogrammic enclosure filled with copper -water nanofluid and subjected to a straight magnetic field. Both the upper and lower inclined walls of the enclosure are kept cold, while its right sidewall is considered fully opened to the environment. The left sidewall of the enclosure is heated partially, while the remaining parts of it are considered thermally insulated. The ranges of this study are, Hartmann number ( $0 \leq \mathrm{Ha} \leq 75)$, nondimensional heat source location $(0.25 \leq \varepsilon \leq 0.75)$, Rayleigh number $\left(10^{4} \leq \mathrm{Ra} \leq 10^{6}\right)$, solid volume fraction $(\phi=0.04)$, and the inclination angle of the upper and the lower walls $\left(-60^{\circ} \leq \lambda \leq 60^{\circ}\right)$. The non-dimensional heat source length is considered fixed at [ $\delta=0.25]$. For all Hartmann numbers, It was found that for $\left[\mathrm{Ra}=10^{6}\right]$, the maximum value of the average Nusselt number corresponds to $\left[-30^{\circ} \leq \lambda \leq 0^{\circ}\right],\left[\lambda=0^{\circ}\right]$ and $\left[0^{\circ}\right.$ $\left.\leq \lambda \leq 30^{\circ}\right]$ when the heat source location equals to $[\varepsilon=0.25],[\varepsilon=0.5]$ and $[\varepsilon=0.75]$ respectively.

\section{Introduction}

Over the past decades, a considerable attention has been devoted to study the natural convection in an open cavity due to their relevance in several industrial applications such as in solar receivers, cooling of electronic equipment's and the thermal building design [1]. One of the prime objectives of the thermal design is to obtain a highly efficiency energy transfer system. As it is known, the natural convection has inherently a weak heat transfer performance due to the absence of any external means of producing the fluid movement as in the forced convection. So, the efficient of the

\footnotetext{
* Corresponding author.

E-mail address: iaghani68@yahoo.com
}

https://doi.org/10.37934/arfmts.74.2.120145 
energy transfer in the natural convection is directly affected by the flow patterns inside the enclosure which are induced by the buoyancy force [2-4]. These flow patterns have a primary consideration when designing the enclosure because creating the right flow pattern is critical to achieving the maximum energy transfer.

The geometrical parameters play also a vital role in enhancing the heat transfer through determining the flow patterns behavior. For instance, the flow behavior may be modified to provide proper flow acceleration through manipulating the geometrical parameters such as the enclosure shape, inclination angle, aspect ratio and the heat source location [5]. Although numerous models of the classical open enclosures [6-24] and non- classical ones [25-27] have been designed by many researchers for investigating and describing the natural convection processes in energy related applications, considerable efforts are still needed to acquire an optimum enclosure design that meet the requirements for the efficient heat transfer process. In fact, one of the most important geometries of the enclosures is the parallelogrammic shape. This complicated geometry has many real applications such as in solar collectors, building structures, electronics thermal control and geothermal applications $[28,29]$. Also, this shape has shown a high response of changing the flow patterns due to the change in its inclination angle [30]. Extensive researches have been conducted on the natural convection in closed parallelogrammic enclosures. Yüncü and Yamac [31] studied numerically the laminar natural convection in an air - filled parallelogrammic enclosure with the horizontal isothermal walls and insulated inclined walls. They analyzed the effects of both the inclination angle and the aspect ratio. The results emphasized that this enclosure transmitted more heat in the forward direction than a rectangular one for the same aspect ratio. In addition, it was also deduced that the average Nusselt number in the forward direction of the parallelogrammic enclosure was higher compared to the backward direction for all considered cases. Later, Naylor and Oosthuizen [32] also investigated the effects of the inclination angle on the natural convection heat transfer within the parallelogrammic enclosure. Calculations were conducted for Rayleigh numbers ranging from $10^{3}$ to $10^{5}$ and a set of wall angles $\left[-60^{\circ} \leq \beta \leq 60^{\circ}\right]$. It was observed that the positive inclination angles showed more uniform distribution of the heat transfer rates than the negative angles. Baïri [33] and Baïri et al., [34] examined numerically and experimentally the natural convection in a closed parallelogrammic air-filled enclosure with three discrete heat sources connected to the adiabatic vertical wall. The results revealed that the parallelogrammic enclosure with positive inclination angle exhibited higher Nusselt number than the right angle enclosure. On contrary, the Nusselt number was reduced for negative angles. The results asserted also that the natural convection was enhanced when the hot wall was entirely active in comparison with that consisted of the discrete heat sources. Villeneuve et al., [35] studied the natural convection in a vertical stack of the parallelogrammic air-filled enclosures. They focused on the potential and the high insulating character of such structures. They showed that the conduction was the dominant heat transfer mode for highly negative inclination angles.

On the other hand, the natural convection under the effect of a magnetic field is of considerable importance in many industrial applications. It is an established physical fact that an externally imposed magnetic field may suppress the natural convection in a conducting fluid [36]. Therefore, the existence of the magneto-hydrodynamics (MHD) leads to a further deterioration in the heat transfer within enclosures. Meanwhile, conventional fluids used for heat transfer applications such as water, mineral oils and ethylene glycol have a rather low thermal conductivity. To overcome this problem, some solid nanoparticles with a high thermal conductivity are added to the fluid to produce a new homogenous mixture called "nanofluid" [37-39]. Recently, the combination between the MHD and the nanotechnology in the heat transfer area such as in fusion, molten steel flow and cooling of nuclear reactors is used as a control element for convective heat transfer [40-42]. Many researchers 
are investigated the MHD natural convection in an open traditional enclosure filled with nanofluid. Kefayati [43] analyzed the magnetic field effect on the natural convection in an open enclosure filled with $\mathrm{Al}_{2} \mathrm{O}_{3}$-water nanofluid. His study was carried out for Rayleigh numbers varied as $\left[10^{4} \leq \mathrm{Ra} \leq 10^{6}\right]$, volume fractions of nanoparticles varied as $[0 \leq \phi \leq 6 \%$ ] and the Hartmann number varied as $[0 \leq \mathrm{Ha}$ $\leq 90]$. The results showed that the increment of the Hartmann number degraded the heat transfer for various Rayleigh numbers and volume fractions. He concluded that the presence of the magnetic field enhanced the effect of nanoparticles at $\mathrm{Ra}=10^{4}$ and $\mathrm{Ha}=30$. Mejri and Mahmoudi [44] examined numerically the natural convection in an open cavity with a sinusoidal thermal boundary condition and filled with $\mathrm{Al}_{2} \mathrm{O}_{3}$ - water nanofluid. The volume fraction varied as $[0 \leq \phi \leq 6 \%$, while the Hartmann number varied as $[0 \leq \mathrm{Ha} \leq 60]$. Their results showed that the heat transfer rate increased with the rise of the Rayleigh number and decreased with the increase of the Hartmann number. Gangawane [45] studied numerically the natural convection in an open square cavity exposed to a magnetic field. One of the vertical walls of the cavity was partially heated at the center, while the other wall was considered open. He investigated the effects of the heater size, Hartmann number, Rayleigh number and the angle of magnetic field on the heat transfer mechanism. It was found that the maximum heat transfer rate was achieved when the magnetic field angle equals to $0^{\circ}$ or $90^{\circ}$, while the lowest one was found at angle $45^{\circ}$. At the same time, the results showed that the impact of the heater size became significant only at $\left[R a=10^{5}\right]$.

From the other side, very limited attempts are carried out of the MHD natural convection in open enclosures with a complex geometry and filled with nanofluid. Bakier [46] investigated numerically the natural convection in an open C-shape cavity filled with nanofluid. The results showed that heat transfer rate increased with the increment of nanoparticles at low Rayleigh number. Miroshnichenko et al., [47] carried out a numerical study of MHD natural convection in an open trapezoidal cavity filled with $\mathrm{CuO}$ - water nanofluid. They studied the effect of the magnetic field intensity and its inclination angle together with the nanoparticles volume fraction on the heat transfer process. Their simulation was performed for a wide range of governing parameters including Rayleigh number $\left[10^{3}\right.$ $\leq \mathrm{Ra} \leq 10^{5}$, , volume fraction $[0 \leq \phi \leq 4 \%]$, Hartmann number $[0 \leq \mathrm{Ha} \leq 100]$ and the magnetic field inclination angle $[0 \leq \alpha \leq \pi]$. The results indicated that the increasing in Hartmann number reduced the heat transfer, while the increase in the nanoparticles volume fraction enhanced it significantly. Ashorynejad and Shahriari [48] studied the MHD natural convection in an open wavy cavity filled with $\mathrm{Al}_{2} \mathrm{O}_{3}-\mathrm{Cu} /$ water hybrid nanofluid. Their results emphasized that the Nusselt number was increased by the increment of the Rayleigh number and nanoparticle volume fraction. Conversely, the increasing in the Hartmann number led to decline the values of the Nusselt number. Very recently, Astanina et al., [49] numerically presented the effects of the Hartmann number, magnetic field inclination angle and nanoparticles volume fraction in an open trapezoidal cavity filled with a ferrofluid. The results revealed that the increasing of the Hartmann number led to the heat conduction domination and a clear reduction in both the heat transfer and ferrofluid rates. More recent studies deal with the nanofluid flow in different geometries [50-54].

However, it can be deduced from the previous extensive literature review, that there is no paper at all studied the effect of the magnetic field on the natural convection in a fully opened parallelogrammic enclosure filled with nanofluid and partially heated from its left sidewall. The geometry of the present paper is a modification of our previous published paper [55]. In the present paper, the linking between the nanotechnology and the magneto-hydrodynamics natural convection for the considered complex geometry represents the original contribution of the present work and this can be considered from our points of view a signification exclusive addition to its field. 


\section{The Physical Problem and the Governing Equations}

Figure 1 displays a detailed sketch of the current problem. The geometry consists of a parallelogrammic enclosure which is considered fully open to the environment form its right sidewall, while it is heated partially from its left one. The rest of the latter wall is considered adiabatic. The upper and lower inclined walls of it are kept cold in order to produce the required temperature difference which is necessary for the natural convection phenomena. The enclosure is filled with a nanofluid consists from the copper nanoparticles immersed in a pure water. The flow in the enclosure is subjected to a straight magnetic field (B) from its right sidewall as shown in Figure 1 . The following assumptions are considered in the mathematical model.

i. Thermo-physical properties of the water are assumed fixed except the density, which is treated according to the Boussinesq approximation.

ii. The flow inside the enclosure is considered two-dimensional, laminar and time invariant.

iii. No slip occurs between the copper nanoparticles and the water and both of them are assumed under a thermodynamic equilibrium state.

Therefore, by considering the above assumptions into account, the dimensionless governing equations of the present problem can be written as follows [56]

$\frac{\partial U}{\partial X}+\frac{\partial V}{\partial Y}=0$

$U \frac{\partial U}{\partial X}+V \frac{\partial U}{\partial Y}=-\frac{\partial P}{\partial X}+\frac{\mu_{n f}}{\rho_{n f} \alpha_{f}}\left(\frac{\partial^{2} U}{\partial X^{2}}+\frac{\partial^{2} U}{\partial Y^{2}}\right)$

$U \frac{\partial V}{\partial X}+V \frac{\partial V}{\partial Y}=-\frac{\partial P}{\partial Y}+\frac{\mu_{n f}}{\rho_{n f} \alpha_{f}}\left(\frac{\partial^{2} V}{\partial X^{2}}+\frac{\partial^{2} V}{\partial Y^{2}}\right)+\frac{(\rho \beta)_{n f}}{\rho_{n f} \beta_{f}} \operatorname{RaPr} \theta-H a^{2} \operatorname{Pr} \frac{\sigma_{n f}}{\sigma_{f}} \frac{\rho_{f}}{\rho_{n f}} V$

$U \frac{\partial \theta}{\partial X}+V \frac{\partial \theta}{\partial Y}=\frac{\alpha_{n f}}{\alpha_{f}}\left(\frac{\partial^{2} \theta}{\partial X^{2}}+\frac{\partial^{2} \theta}{\partial Y^{2}}\right)$

The properties of the Copper - water nanofluid, and the nanofluid properties equations are illustrated in Table 1 and Table 2, respectively. From the other hand, the dimensionless horizontal and vertical velocities can be related to the dimensionless stream function as follows [57]

$U=\frac{\partial \psi}{\partial Y}$ and, $V=-\frac{\partial \psi}{\partial X}$

The non-dimensional variables are given by $[42,58]$

$$
\begin{aligned}
& X, Y=\frac{X, Y}{H}, \theta=\frac{T-T_{C}}{T_{h}-T_{C}}, P=\frac{p H^{2}}{\rho_{n f \alpha_{f}^{2}}},(U, V)=\frac{(u, v) H}{\alpha_{f}}, \psi=\frac{\Psi}{\alpha_{f}} \\
& R a=\frac{\rho \beta_{f}\left(T_{h}-T_{C}\right) H^{3}}{\vartheta_{f} \alpha_{f}}, P r=\frac{\vartheta_{f}}{\alpha_{f}}, H a=B \times H \sqrt{\frac{\sigma_{f}}{\rho_{f} \vartheta_{f}}}, \varepsilon=\frac{d}{H}, \delta=\frac{h_{b}}{H}
\end{aligned}
$$


The non-dimensional boundary conditions are given by

Left wall

$X=0, \varepsilon-\frac{\delta}{2} \leq Y \leq \varepsilon+\frac{\delta}{2}$

$U, V=0, T=1$

$X=0,0<Y<\varepsilon-\frac{\delta}{2}, \varepsilon+\frac{\delta}{2}<Y<1$

$U, V=0, \frac{\partial T}{\partial X}=0$

\section{Right side (Opening)}

$X=\cos \alpha, \sin \alpha \leq Y \leq \sin \alpha+1$

Fluid enters to the enclosure $\quad(U<0)$

$$
\frac{\partial U}{\partial X}=0, V=0, \theta=0
$$

Fluid exits from the enclosure $\quad(U>0)$

$$
\frac{\partial U}{\partial X}=0, V=0, \frac{\partial \theta}{\partial X}=0
$$

Lower wall

$0 \leq X \leq \cos \alpha, 0 \leq Y \leq \sin \alpha$

$$
U, V=0, \theta=0
$$

Upper wall

$0 \leq X \leq \cos \alpha, 1 \leq Y \leq \sin \alpha+1$

$$
U, V=0, \theta=0
$$

The local Nusselt number on the source can be calculated from the following relation

$$
N u=-\frac{k_{n f}}{k_{f}}\left(\frac{\partial \theta}{\partial X}\right)
$$

The average Nusselt Number on the source is calculated from

$$
N u_{a v}=\frac{1}{\varepsilon} \int_{\varepsilon-\frac{\delta}{2}}^{\varepsilon+\frac{\delta}{2}} N u \cdot d \mathrm{Y}
$$




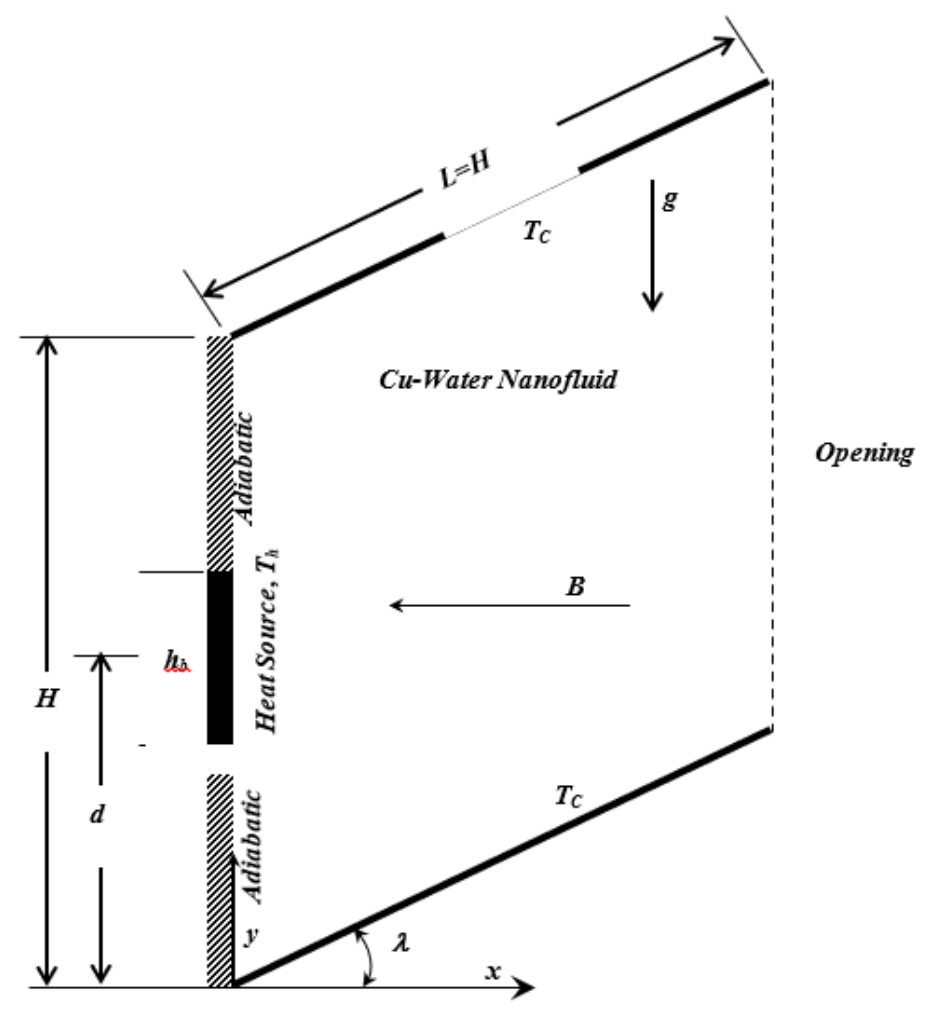

Fig. 1. Sketch of the Physical Geometry

Table 1

Thermo-physical properties of water and Cu nanoparticles at $300 \mathrm{~K}$ [50]

\begin{tabular}{lll}
\hline Property & Water & Cu-nanoparticle \\
\hline $\mathrm{Cp}(\mathrm{j} / \mathrm{Kg} . \mathrm{K})$ & 4179 & 358 \\
$\mathrm{k}(\mathrm{W} / \mathrm{m} . \mathrm{K})$ & 0.613 & 401 \\
$\rho\left(\mathrm{Kg} / \mathrm{m}^{3}\right)$ & 997.1 & 8933 \\
$\beta\left(\mathrm{K}^{-1}\right)$ & $21^{*} 10^{-5}$ & $1.67^{*} 10^{-5}$ \\
\hline
\end{tabular}

Table 2

Nanofluid properties equations $[37,59]$

\begin{tabular}{|c|c|}
\hline Nanofluid Property & Equation \\
\hline$\rho_{n f}$ & $(1-\emptyset) \rho_{f}+\emptyset \rho_{s}$ \\
\hline & $\mu_{f} \times(1-\emptyset)^{-2.5}$ \\
\hline$(\rho \beta)_{n f}$ & $\emptyset \rho_{s} \beta_{s}+(1-\emptyset) \rho_{f} \beta_{f}$ \\
\hline$\sigma_{n f}$ & {$\left[3\left(\frac{\sigma_{s}}{\sigma_{f}}-1\right) \emptyset\right.$} \\
\hline & $\sigma_{f}\left[1+\overline{\left(\frac{\sigma_{s}}{\sigma_{f}}+2\right)-\left(\frac{\sigma_{s}}{\sigma_{f}}-1\right) \emptyset}\right]$ \\
\hline$\alpha_{n f}$ & $k_{n f}$ \\
\hline$\rho_{n f} c_{p n f}$ & $\begin{array}{l}\rho_{n f} c_{p n f} \\
(1-\emptyset) \rho_{f} c_{p f}+\emptyset \rho_{s} c_{p s}\end{array}$ \\
\hline$k_{n f}$ & $k_{n f}=k_{f}\left[\frac{k_{s}+2 k_{f}-2 \emptyset\left(k_{f}-k_{s}\right)}{k_{s}+2 k_{f}+\emptyset\left(k_{f}-k_{s}\right)}\right]$ \\
\hline
\end{tabular}

\section{Numerical Approach, Grid Independent Test and Validation}

Since the considered geometry of the enclosure is very complex and cannot be treated easily, the body fitted coordinates system is a very good way to deal with this problem. FORTRAN code has been 
used to solve the governing equations in dimensionless forms using a finite volume approach with SIMPLER algorithm. The details of this system are explained in more details in [59] and cannot be repeated here for the purpose of the brevity. In order to solve the non-dimensional governing equations [Eq. (1)-(4)], the finite volume method is used to achieve the required numerical solution. The results are produced by a personal computer program which is written completely in Fortran 90 language by the present authors. The results are obtained and transferred to a data files after the convergence criterion becomes less or equals than $10^{-6}$. In order to be sure from the accuracy of the predicated results, a comparison with another numerical problem is performed. For this purpose, the problem of the natural convection in a differentially heated square enclosure filled with $\mathrm{Al}_{2} \mathrm{O}_{3}$-water nanofluid and subjected to a horizontal magnetic field (Ghasemi et al., [60]) is re-tested again by our computer program. The validation is done at $[\mathrm{Ha}=30]$ and $\left[\mathrm{Ra}=10^{5}\right]$ and with different solid volume fractions $(0 \leq \phi \leq 0.06)$. Table 3 displays the results of this comparison and exhibits an excellent matching between the two results. From another side, the effect of the grid size is examined to choose the suitable grid density between a various range of the grid size varied from $(32 \times 32)$ to $(48$ $\times 48)$ as shown in Table 4. The test is performed for the parallelogrammic enclosure at $(\lambda=-60)$, (Ra $\left.=10^{5}\right),(\varepsilon=0.5),(\phi=0.04)$ and $(\mathrm{Ha}=50)$. It is observed from the grid independence test that an $(48 \times$ 48) grid size is very fair to deal with the present problem. Since at this value, the estimated error in the average Nusselt number is about (0.64 \%).

Table 3

Comparison of the average Nusselt number with previous numerical study of Ghasemi et al., [60] at [ $\mathrm{Ha}=30],\left[\mathrm{Ra}=10^{5}\right]$ and $[0 \leq \phi \leq 0.06]$

\begin{tabular}{llll}
\hline$\phi$ & Ghasemi et al., [60] & Present & Error (\%) \\
\hline 0 & 3.15 & 3.134 & 0.51 \\
0.02 & 3.138 & 3.12 & 0.57 \\
0.04 & 3.124 & 3.103 & 0.67 \\
0.06 & 3.108 & 3.08 & 0.9 \\
\hline
\end{tabular}

Table 4

Grid independent test for parallelogrammic enclosure at $(\lambda=-60),(\mathrm{Ra}=105),(\varepsilon=$ $0.5),(\phi=0.04)$ and $(\mathrm{Ha}=50)$

\begin{tabular}{llll}
\hline CVs & $32 \times 32$ & $40 \times 40$ & $48 \times 48$ \\
\hline Nuav & 1.51 & 1.56 & 1.57 \\
Error (\%) & - & 3.31 & 0.64 \\
\hline
\end{tabular}

\section{Results and Discussion}

In general, the natural convection currents inside the parallelogrammic open enclosure are produced by the buoyancy force as a result of the temperature difference between the hot spot in the center of the left sidewall of the enclosure and the colder pure or nanofluids which is entering the enclosure from the opening at its right sidewall. Therefore, the flow starts from this hot spot since its temperature is high and the buoyancy force tries to move the hot light fluid adjacent the cold upper wall. After that, the hot fluid encounters in its way a cold one comes from the enclosure opening. So, its temperature begins to diminish clearly and as a result becomes heavier due to its high density and moves towards the lower wall producing the well - known convection vortices inside the enclosure. In the following sub-sections, the effects of the Hartmann number $(0 \leq \mathrm{Ha} \leq 75)$, nondimensional heat source location $(0.25 \leq \varepsilon \leq 0.75)$, Rayleigh number $\left(10^{4} \leq \mathrm{Ra} \leq 10^{6}\right)$ and inclination angles $\left(-60^{\circ} \leq \lambda \leq 60^{\circ}\right)$ on the flow, thermal fields and the average Nusselt number are discussed 
in more details. While, the non-dimensional heat source length is considered constant at $\delta=0.25]$. In all the presented results, the continuous lines refer to the water $(\phi=0)$, while the dashed lines refer to the nanofluid $(\phi=0.04)$.

\subsection{Effect of the Hartmann Number on the Streamlines and Isotherms}

Figure 2 and Figure 3 show respectively the streamlines and isotherms for both water and nanofluid at various Hartmann numbers $(0 \leq \mathrm{Ha} \leq 75)$ and inclination angles $\left(-60^{\circ} \leq \lambda \leq 60^{\circ}\right)$ when $\left[R a=10^{5}\right]$ and $[\varepsilon=0.25]$. The magnetic field effect on the flow and thermal fields can be measured via the Hartmann number. For the case of the negligible magnetic field or $(\mathrm{Ha}=0)$, the absolute values of the stream function for both water and nanofluid reach their maximum value for all range of the inclination angle. The highest values of the stream function can be seen at $\left[=30^{\circ}\right]$ for both water and nanofluid. The reason of this behavior is due to the strong effect of the natural convection when the magnetic field is absent. In this case, the buoyancy force becomes the major and the only governor of the flow field inside the enclosure. Now, as the Hartmann number increases gradually until it reaches $(\mathrm{Ha}=75)$, a severe drop in the stream function values can be noticed compared with their corresponding values at $(\mathrm{Ha}=0)$. For example, at $\left[\lambda=30^{\circ}\right]$, the maximum value of the stream function (absolute value of the minimum value shown in Figure 2 ) decreases for water from $\left[|\psi|_{\max }=\right.$ 28.96] at $(\mathrm{Ha}=0)$ to $\left[|\psi|_{\max }=2.209\right]$ at $(\mathrm{Ha}=75)$. While, it decreases at the same angle for the nanofluid from $\left[|\psi|_{\max }=27.91\right]$ at $(\mathrm{Ha}=0)$ to $\left[|\psi|_{\max }=1.777\right]$ at $(\mathrm{Ha}=75)$. The main reason behind this severe decreasing in the stream function values is due to the high effect of the Lorentz force which is generated due to the magnetic field acts in the normal direction of the fluid flow inside the enclosure. This force acts in the opposite direction of the fluid flow and weaknesses the normal velocity component. Therefore, when the Hartmann number becomes high ( $\mathrm{Ha}=75)$, the effect of this force becomes stronger and exceeds the buoyancy force effect and as a result decreases sharply the values of the stream function as shown in Figure 2 which leads to slow the fluid flow inside the enclosure.

From the other hand, it can be seen that for positive values of the inclination angle [i.e., $\lambda=30^{\circ}$ and $60^{\circ}$ ] and as $(\mathrm{Ha})$ increases, the exit fluid from the enclosure begins to leave it horizontally from the opening at its right sidewall. While, the inlet fluid stays parallel to the inclined wall. This is due to the increase in the applied horizontal magnetic force which leads to decrease the normal velocity component as mentioned previously and this obliges the fluid to leave the enclosure horizontally. On the reverse manner, for negative values of the inclination angle [i.e., $\lambda=-30^{\circ}$ and $-60^{\circ}$ ] and as $(\mathrm{Ha})$ increases, the inlet fluid to the enclosure begins to enter it horizontally. While, the exit fluid remains parallel to the inclined wall. This is for the same reason explained above, but in an opposite way due to the negative values of the inclination angle.

With respect to isotherms, it can be seen from the results of Figure 3, that they are irregular in their pattern and clustered with a strong intensity adjacent the left sidewall of the enclosure due to the existence of the hot spot in this wall. This behavior is noticed when there is no magnetic field [i.e., $\mathrm{Ha}=0$ ]. The reason of this behavior is very logical since in this case the natural convection is strong and leads to make the isotherms non-uniform and curved especially in the core of the enclosure. Similar observation can be noticed for both water and nanofluid and for all inclination angles. Now, as the magnetic field becomes more effective [i.e., $\mathrm{Ha}=75$ ] a clear switch in the isotherms pattern can be seen. They become more elegant, uniform and parallel to each other. Again, this is a logical result because the strong magnetic field damps highly the natural convection effect and as a result makes the heat transferred inside the enclosure via heat conduction only. This behavior can be noticed also for all inclination angles and for both water and nanofluid. 


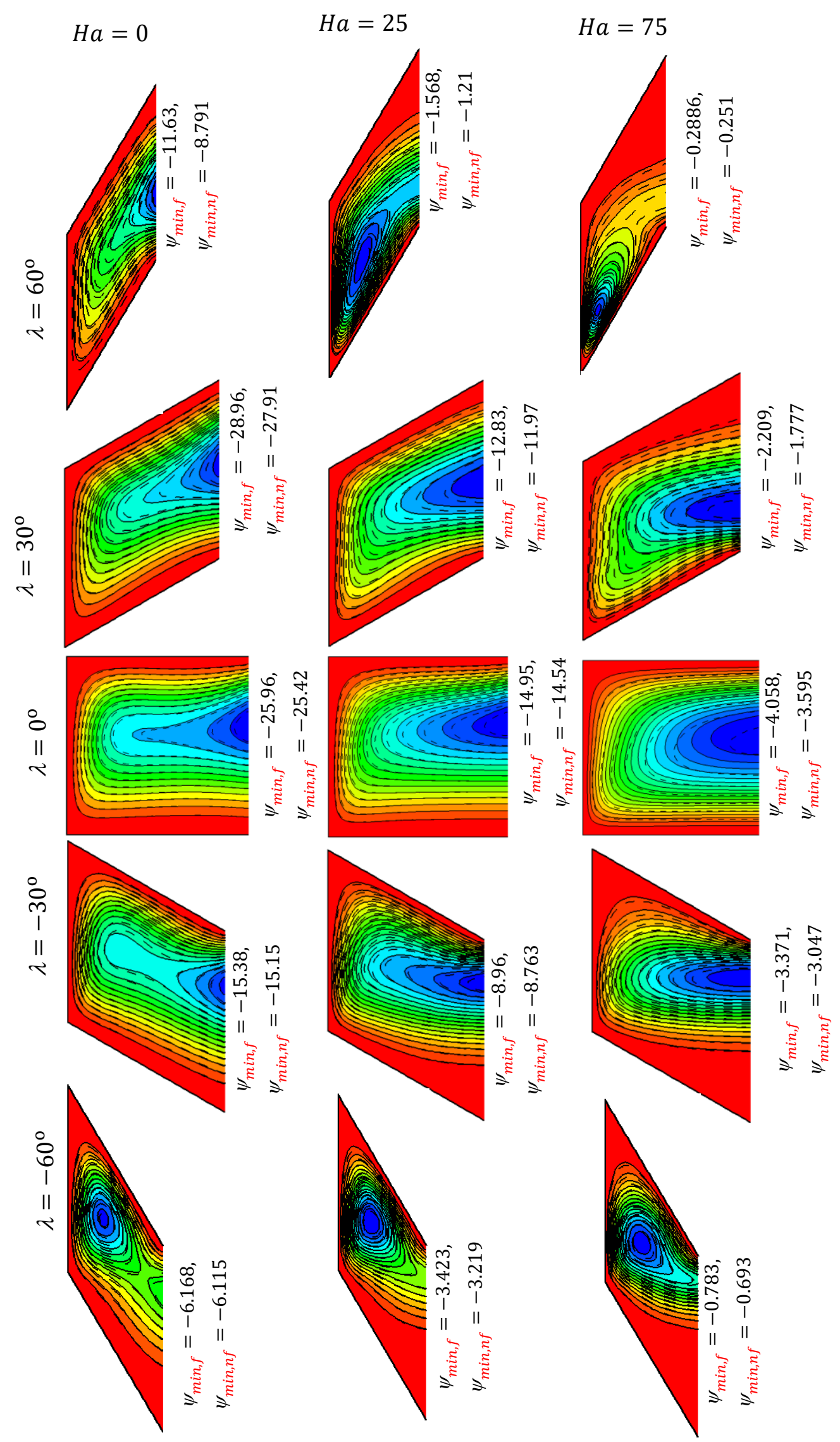

Fig. 2. Streamline contours for various Hartmann numbers and inclination angles at $\mathrm{Ra}=105$ and $\varepsilon=0.25$ [pure fluid ( ), nanofluid (- - - - )] 


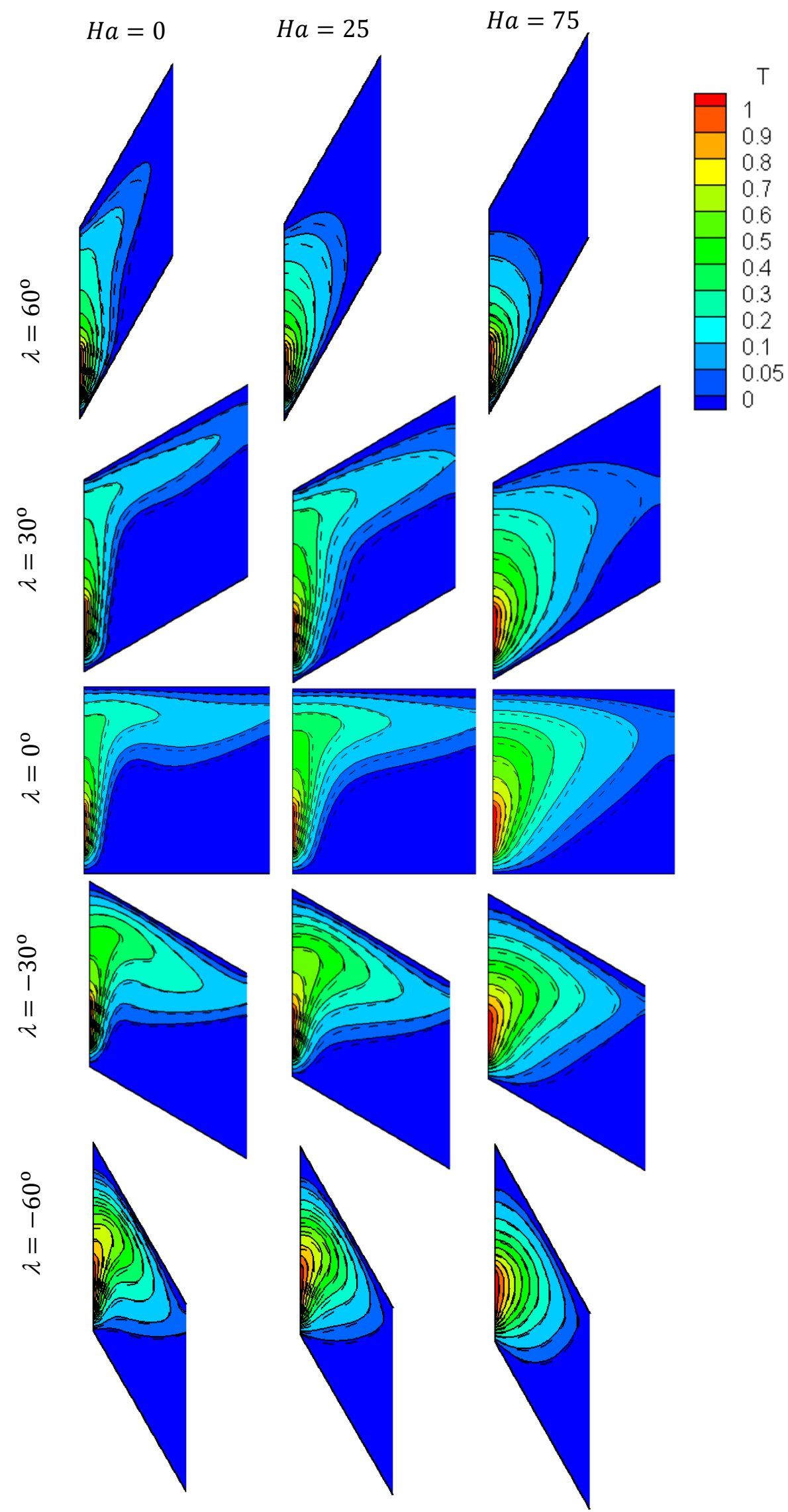

Fig. 3. Isotherm contours for various Hartmann numbers and inclination angles at $\mathrm{Ra}=10^{5}$ and $\varepsilon=0.25$ [pure fluid ), nanofluid (- - - - -)] 


\subsection{Effect of the Non-Dimensional Heat Source Location on the Streamlines and Isotherms}

Figure 4 and Figure 5 show respectively the streamlines and isotherms for both water and nanofluid at various non-dimensional heat source locations $(0.25 \leq \varepsilon \leq 0.75)$ and inclination angles ($\left.60^{\circ} \leq \lambda \leq 60^{\circ}\right)$ when $\left[\mathrm{Ra}=10^{5}\right]$ and $[\mathrm{Ha}=0]$. It can be seen that for all values of the heat source location and inclination angles, the water or nanofluid enters the enclosure and leaves it parallel to the upper and lower inclined walls. For $\left[\lambda=60^{\circ}\right]$, it can be noted that the maximum value of the stream function increases for both water and nanofluid as the heat source location increases from $[\varepsilon$ $=0.25]$ to $[\varepsilon=0.75]$. Now, when the inclination angle decreases to $\left[\lambda=30^{\circ}\right]$, the stream function also increases up to the location $[\varepsilon=0.5]$ and then begins to decrease at the location $[\varepsilon=0.75]$. Now, when the inclination angle decreases to $\left[\lambda=30^{\circ}\right]$, the stream function also increases up to the location $\left[\varepsilon=0.5\right.$ ] and then begins to decrease at the location $[\varepsilon=0.75]$. For $\left[\lambda=0^{\circ}\right.$ ], they begin to decrease immediately as the heat source location increases. In addition, the stream function decreases as the heat source location increases for the negative inclination angles. Therefore, it can be concluded that for negative inclination angles, the natural convection diminishes when the heat source location increases. While for the highest value of the positive inclination angles [i.e., $\lambda=60^{\circ}$ ], it enhances as the heat source location increases. Also, it can be observed that for negative inclination angles only, a vortex will appear inside the enclosure and begins to move towards the left corner of the upper inclined wall. This movement is seen as the heat source changes its location from the lower position $[\varepsilon=0.25]$ to the upper one $[\varepsilon=0.75]$. Moreover, the results presented in Figure 4 indicated that the optimum heat source location occurs at $[\varepsilon=0.5]$ or when the heat source is located at the middle of the enclosure and at $\left[\lambda=30^{\circ}\right]$. Since at these values, the stream function reaches its highest value for both water and nanofluid.

With respect to isotherms, it can be seen from the results of Figure 5, that they are very influenced by the movement of the heat source location. Therefore, it can be seen that the isotherms are clustered intensely at the lower region of the left sidewall, when the heat source located at this region [i.e., $\varepsilon=0.25$ ]. Now, as the heat source reaches the middle of the enclosure $[\varepsilon=0.5]$, the isotherms are clustered and embedded at this place. After that they are observed at the upper region of the left sidewall, when the heat source is located there [i.e., $\varepsilon=0.75$ ]. Similar pattern of isotherms is found for both water and nanofluid and for the all considered range of the inclination angles. Also, it can be concluded that for inclination angles equal to $\left[\lambda=-30^{\circ}, 0^{\circ}, 30^{\circ}\right.$ and $\left.60^{\circ}\right]$ that the thermal boundary layer for nanofluid (dashed lines) is thicker than the corresponding layer for the water (continuous lines). While, both layers are approximately symmetrical at $\left[\lambda=-60^{\circ}\right]$ and this can be approved by the excellent matching between the dashed and continuous lines at this angle. 
$\varepsilon=0.25$
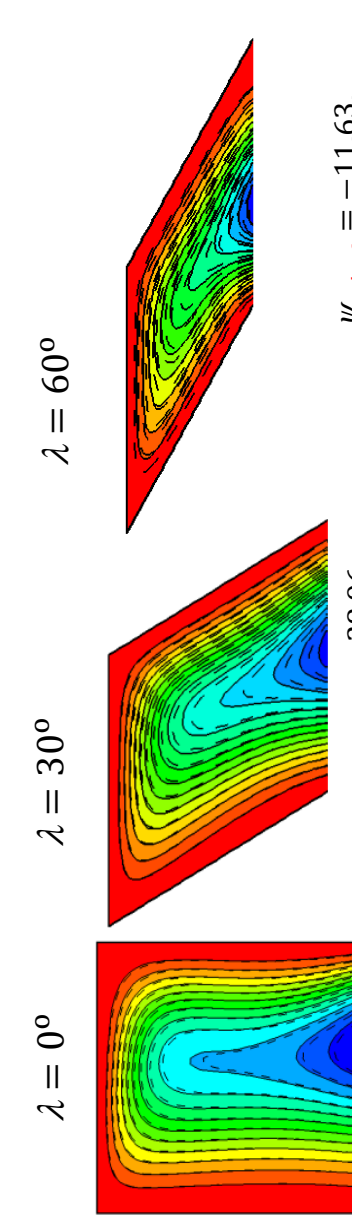

$\circ$
$\stackrel{\circ}{m}$
1
$\stackrel{2}{\rightleftharpoons}$
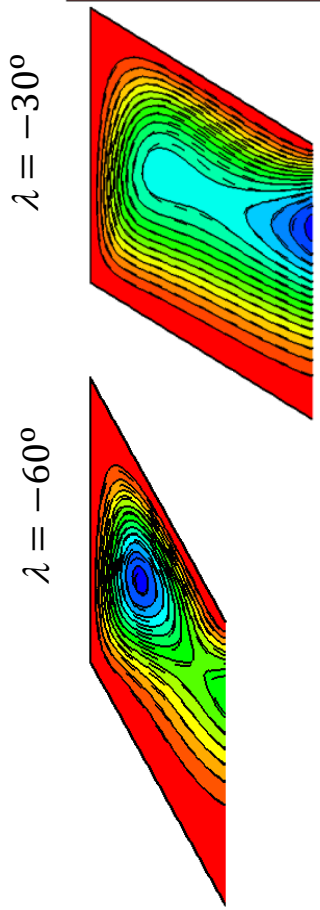

$\varepsilon=0.5$

$\varepsilon=0.75$
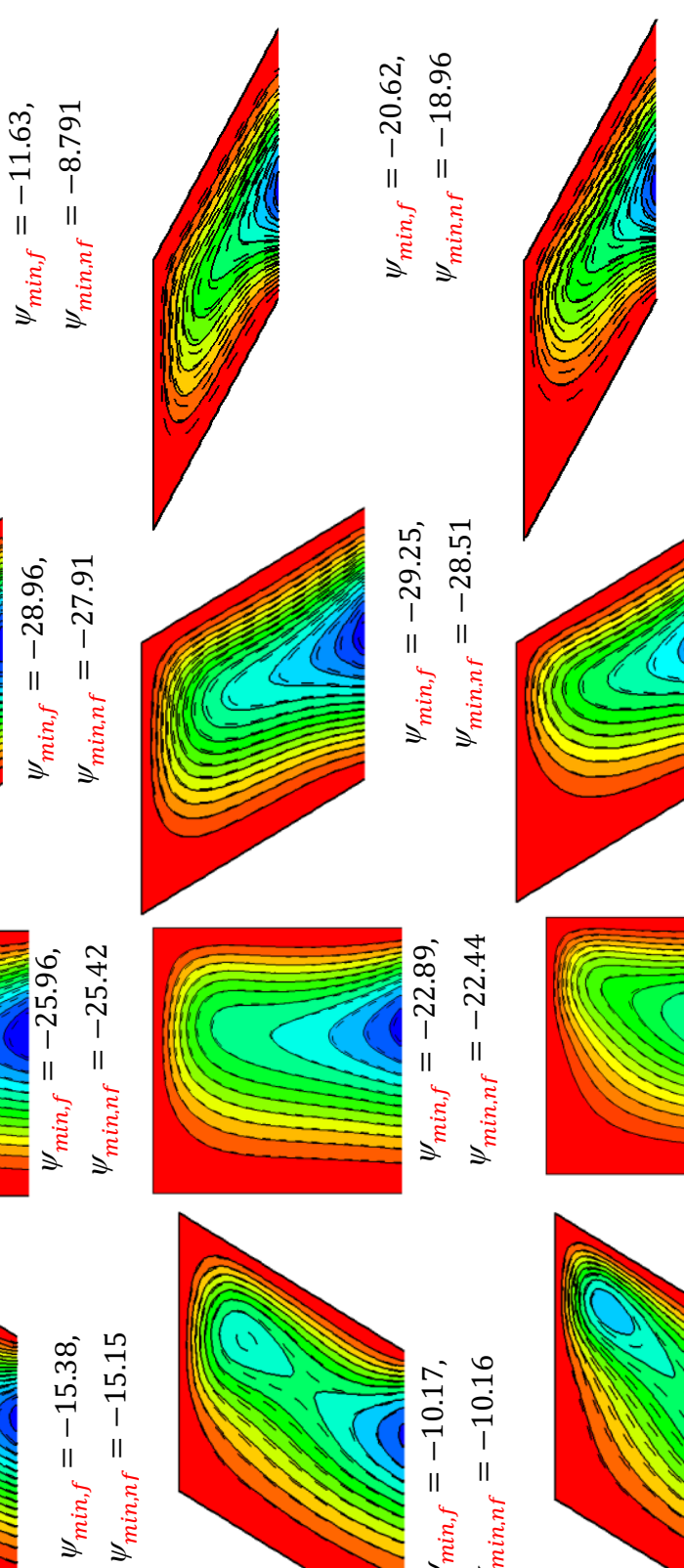

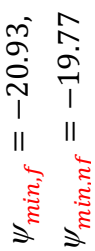

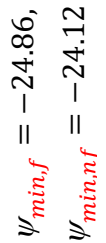
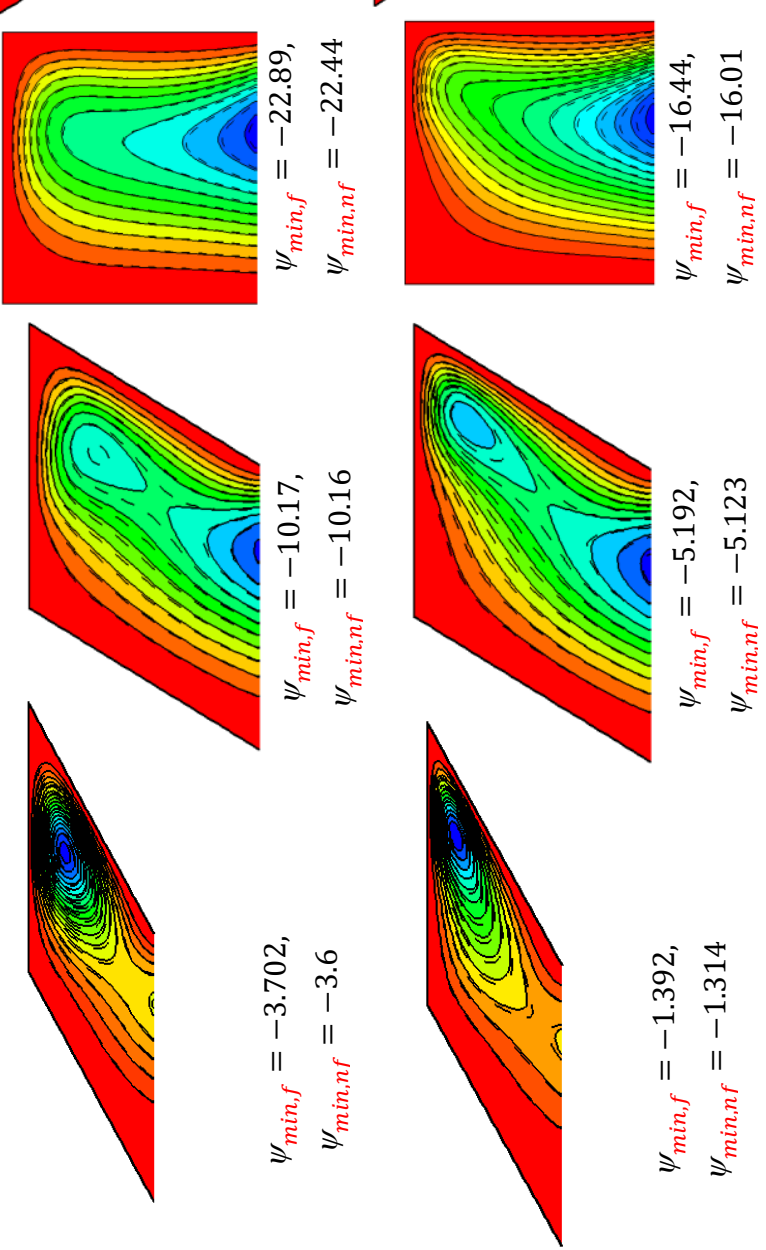

Fig. 4. Streamline contours for various non-dimensional heat source location and inclination angles at $\mathrm{Ra}=105$ and $\mathrm{Ha}=0$ [pure fluid (__ nanofluid (- - - - )] 


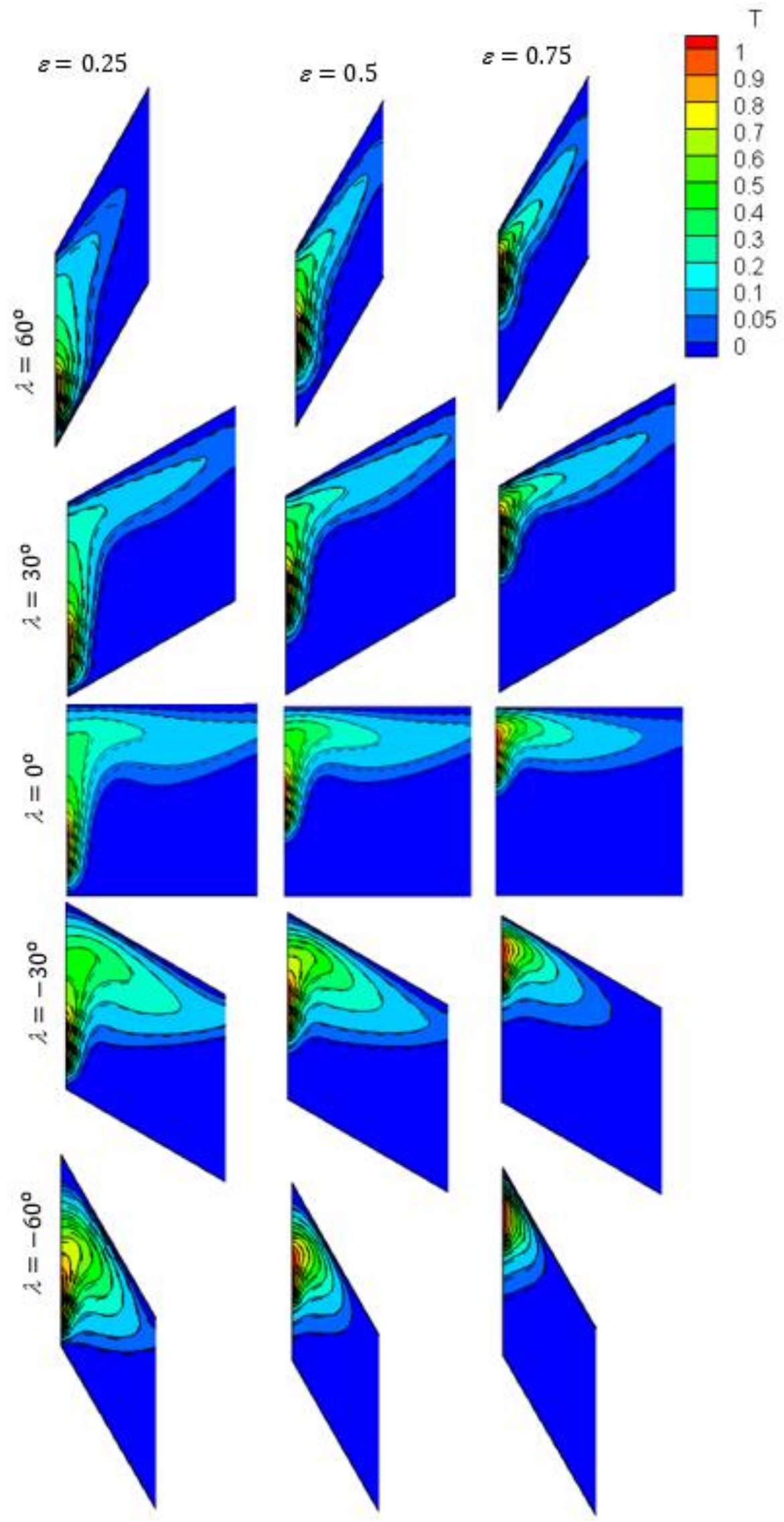

Fig. 5. Isotherms at $\mathrm{Ra}=10^{5}$ and $\mathrm{Ha}=0$ for different heat source positions and different inclination angles. Pure fluid (__ $)$, Nanofluid (- - - -) 


\subsection{Effect of the Rayleigh Number on the Streamlines and Isotherms}

Figure 6 and Figure 7 display respectively the streamlines and isotherms for both water and nanofluid at various Rayleigh numbers $\left(10^{4} \leq \mathrm{Ra} \leq 10^{6}\right)$ and inclination angles $\left(-60^{\circ} \leq \lambda \leq 60^{\circ}\right)$ at $[\mathrm{Ha}$ $=0]$ and $[\varepsilon=0.25]$. The Rayleigh number is an excellent indication of the natural convection intensity. It can be seen from the results presented in Figure 6, that the flow circulation inside the enclosure which is represented by values of the stream function is so weak when the value of the Rayleigh number is low $\left[\mathrm{Ra}=10^{4}\right]$. The reason of this behavior is due to the dominance of the viscous force on the flow circulation compared with the buoyancy force. This notation can be observed for all range of the inclination angle. But this behavior is completely changed when the Rayleigh number is increased to $\left[\mathrm{Ra}=10^{6}\right]$. Therefore, it can be observed in this case that there is a dramatic jump in the values of the stream function for both water and nanofluid. For example, at [ $\lambda=30^{\circ}$ ], the maximum value of the stream function increases for water from $\left[|\psi|_{\max }=5.444\right]$ at $\left(\mathrm{Ra}=10^{4}\right)$ to $\left[|\psi|_{\max }=81.78\right]$ at $\left(\mathrm{Ra}=10^{6}\right)$. Also, it increases at the same angle for the nanofluid from $\left[|\psi|_{\max }=4.581\right]$ at $\left(\operatorname{Ra}=10^{4}\right)$ to $\left[|\psi|_{\max }=78.46\right]$ at $\left(\mathrm{Ra}=10^{6}\right)$. The same thing can be seen for another considered inclination angles. This huge increasing in the flow circulation can be go back to the strong effect of the buoyancy force for high Rayleigh number which causes to make the natural convection inside the enclosure stronger. Moreover, it can be noticed from the results of Figure 6 , that the maximum value of the stream function for both water and nanofluid increases as the positive inclination angle decreases from [ $\lambda$ $\left.=60^{\circ}\right]$ to $\left[\lambda=30^{\circ}\right]$. While, it decreases as the negative inclination angle decreases from $\left[\lambda=-30^{\circ}\right]$ to $\left[\lambda=-60^{\circ}\right]$. Furthermore, it is useful to mention that when the Rayleigh number increases, a vortex will appear and begins to move towards the left sidewall, and this occurs for the negative inclination angles. From another side, the isotherms for both water and nanofluid are illustrated in Figure 7 for the same considered range of the Rayleigh numbers and the inclination angles. When the value of the Rayleigh number is low $\left[\mathrm{Ra}=10^{4}\right]$, the heat is transferred inside the enclosure by the conduction heat transfer.

This fact can be approved by the uniform and parallel symmetrical lines which accumulated near the left sidewall of the enclosure. This intense accumulation of the isotherms in this spot is due to the severe temperature gradient in it. As the isotherms move far away from the hot spot, their intense accumulation begins to decrease step by step and this observation can be indicated by the clear diverge between the isotherms especially in the center of the enclosure. Now, when the value of the Rayleigh number increases until it reaches $\left[\mathrm{Ra}=10^{6}\right.$, an evident twisting in the isotherm patterns can be noticed for both water and nanofluid. The main source of this change is of course due to the enlarge and the significant contribution of the natural convection at $\left[\mathrm{Ra}=10^{6}\right.$ which leads to break the uniform shape of isotherms and make them more irregular as seen in Figure 7. This isotherms style can be noticed for all positive and negative inclination angles. When the value of the Rayleigh number is low $\left[\mathrm{Ra}=10^{4}\right]$, the heat is transferred inside the enclosure by the conduction heat transfer. This fact can be approved by the uniform and parallel symmetrical lines which accumulated near the left sidewall of the enclosure. This intense accumulation of the isotherms in this spot is due to the severe temperature gradient in it. As the isotherms move far away from the hot spot, their intense accumulation begins to decrease step by step and this observation can be indicated by the clear diverge between the isotherms especially in the center of the enclosure. Now, when the value of the Rayleigh number increases until it reaches $\left[\mathrm{Ra}=10^{6}\right]$, an evident twisting in the isotherm patterns can be noticed for both water and nanofluid. The main source of this change is of course due to the enlarge and the significant contribution of the natural convection at $\left[R a=10^{6}\right]$ which leads to break the uniform shape of isotherms and make them more irregular as seen in Figure 7. This isotherms style can be noticed for all positive and negative inclination angles. 


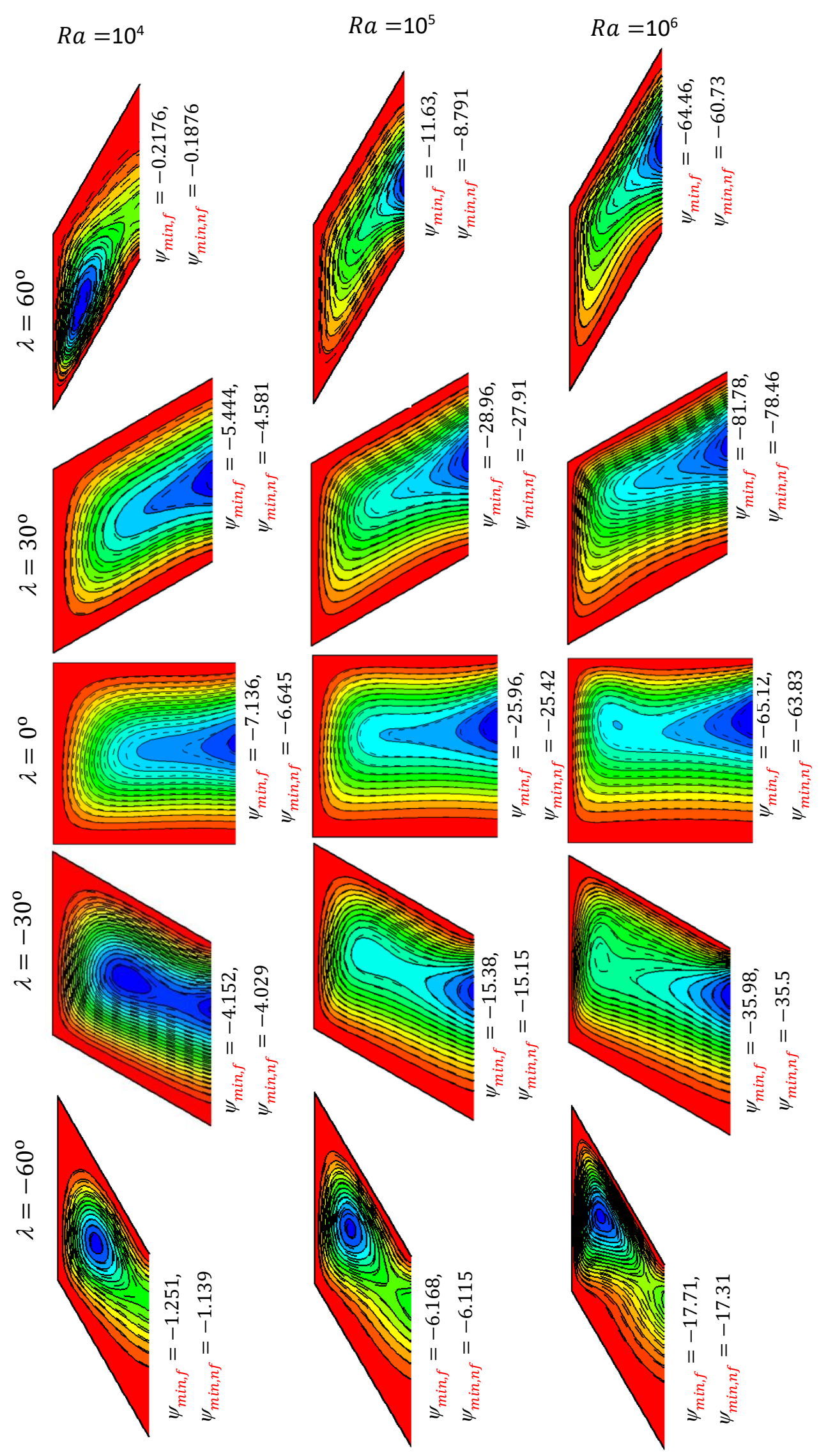

Fig. 6. Streamline contours for various Rayleigh numbers and inclination angles at $\mathrm{Ha}=0$ and $\varepsilon=0.25$ [ pure fluid ( ), nanofluid (-- - - )] 


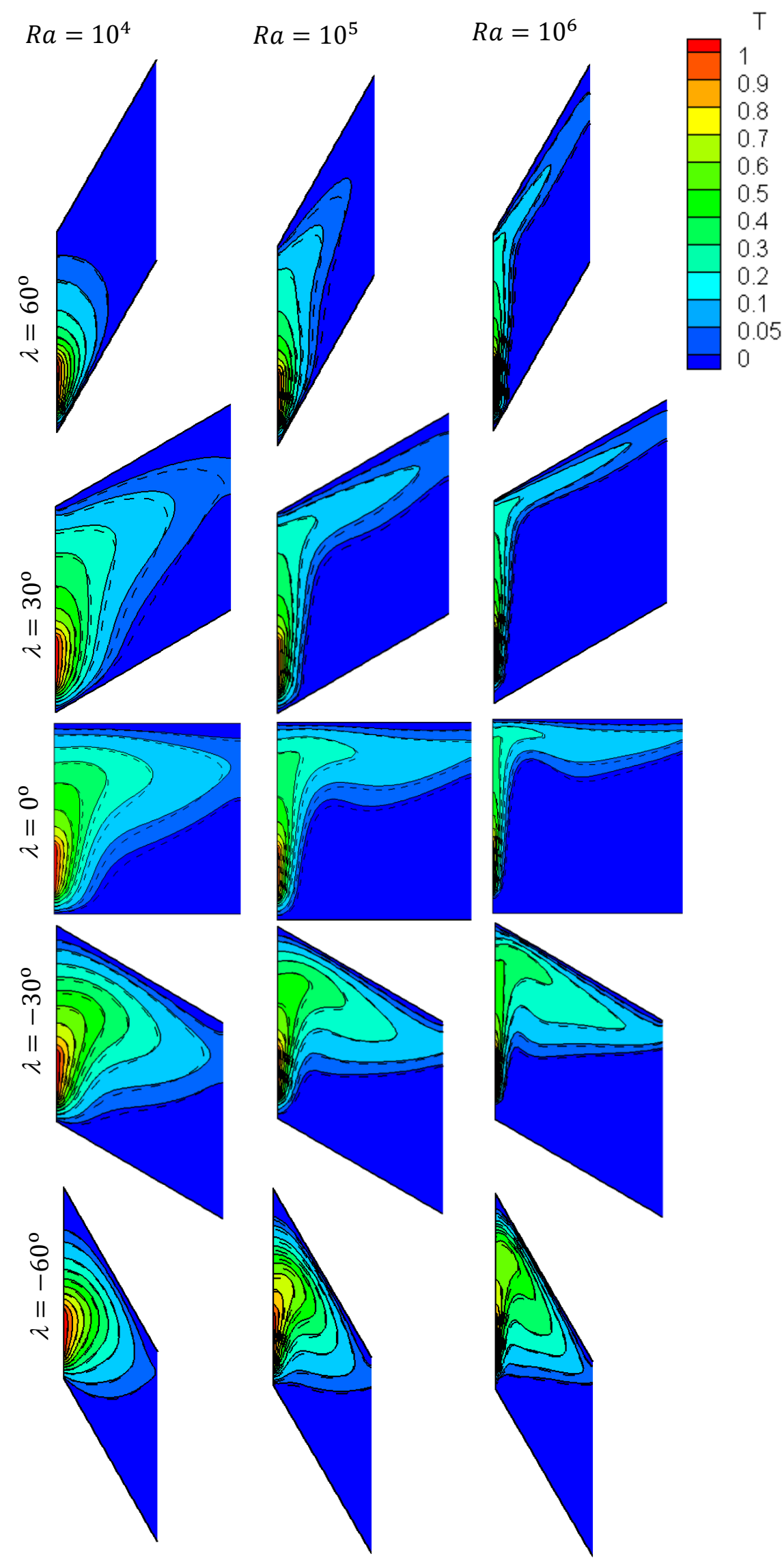

Fig. 7. Isotherm contours for various Rayleigh numbers and inclination angles at $\mathrm{Ha}=0$ and $\varepsilon=0.25$ [ pure fluid ( ), nanofluid (- - - - -)] 


\subsection{Average Nusselt Number Results}

The present study evaluates the effect of the cavity inclination and heat source position on the heat transfer performance in the presence of both magnetic field and nanoparticle at various Rayleigh numbers. This section demonstrates these effects on the average Nusselt number ad in following subsections.

\subsubsection{The effect of magnetic field (Hartmann number)}

Figure 8 and Figure 9 display the average Nusselt number variation with the inclination angle for both water $(\phi=0)$ and nanofluid $(\phi=0.04)$ at different Hartmann numbers and heat source locations ((a) $\varepsilon=0.25$, (b) $\varepsilon=0.5$ and (c) $\varepsilon=0.75$ ) for Rayleigh numbers ( $R a=10^{4}$, Ra $=10^{5}$ and $\mathrm{Ra}=10^{6}$ ) respectively. In general, it can be observed that the highest value of the average Nusselt number occurs for the case of the negligible magnetic field or $(\mathrm{Ha}=0)$ and as the Hartmann number increases, the values of the average Nusselt number begin to diminish clearly until they reach their lowest value at $(\mathrm{Ha}=75)$. So, it can be concluded that the minimum average Nusselt number corresponds to the maximum Hartmann number and vice versa. This behavior is returned to the damping effect of the magnetic field which causes a severe slowdown in the flow circulation inside the enclosure as clearly shown in streamline contours in Figure 2, Figure 4 and Figure 6 . On the other hands, it can be seen that the isotherms contours accumulate strongly adjacent the hot left sidewall as the Hartmann number decreases indicating a reduction in thermal boundary layer thickness due to increasing in flow circulation as shown in Figure 3. The lowest Nusselt number achieved (0.98) at $\mathrm{Ra}=10^{4}$ with Hartmann number $(\mathrm{Ha}=0.75)$. While the maximum Nusselt number reached (6.46) at $\mathrm{Ra}=10^{6}$ with Hartmann number $(\mathrm{Ha}=0)$.

\subsubsection{The effect of nanoparticles}

Figure 8, Figure 9 and Figure 10 illustrate the effects of adding nanoparticles to the water. In general, the results revealed that adding nanoparticles reduces the flow circulation due to enhancing in nanofluid density as seen in Figure 2, Figure 4 and Figure 6. However, the Nusselt numbers of nanofluid show more enhancement compared with that of pure water. This can be attributed to the higher thermal conductivity of the nanoparticles which leads to increase the transport of the thermal energy inside the enclosure. The above behaviors of the average Nusselt number are seen for all values of the inclination angle and the heat source locations. 

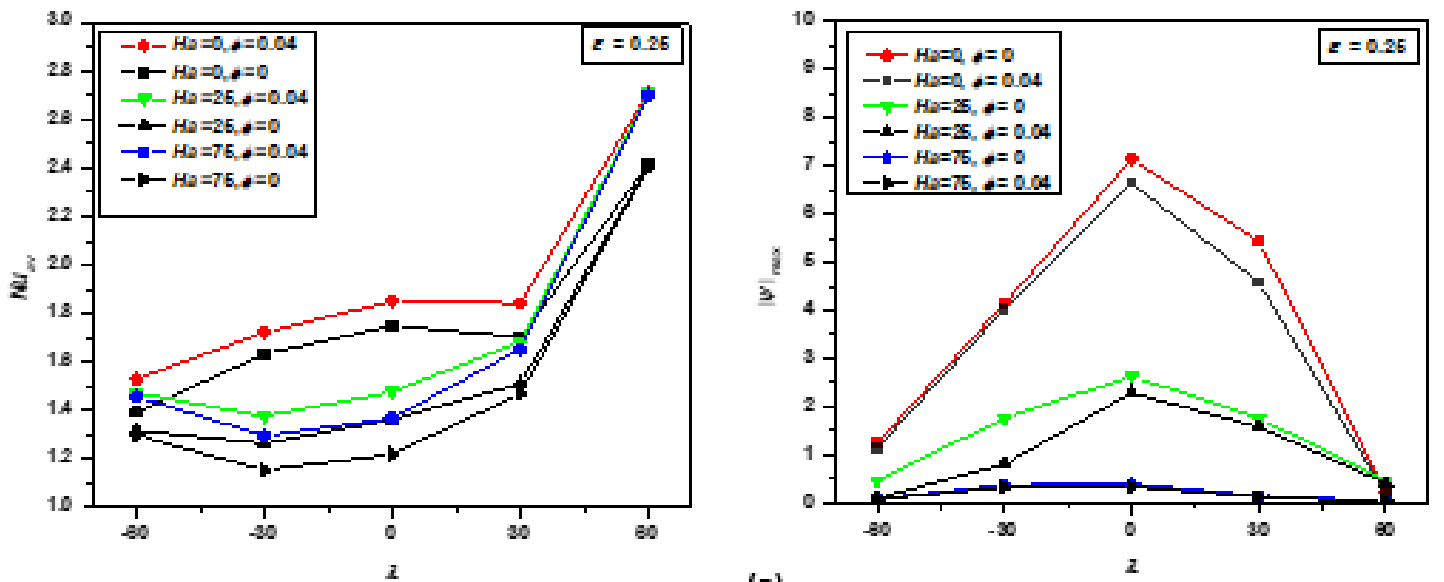

(a)
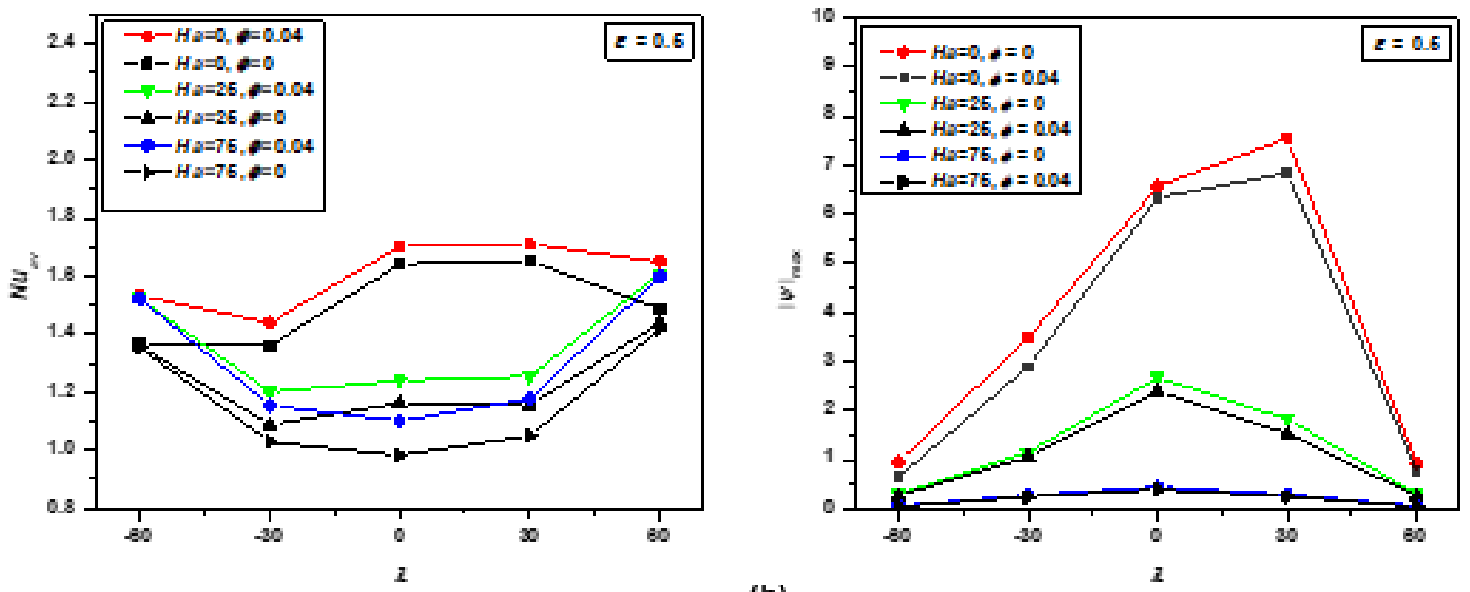

(b)
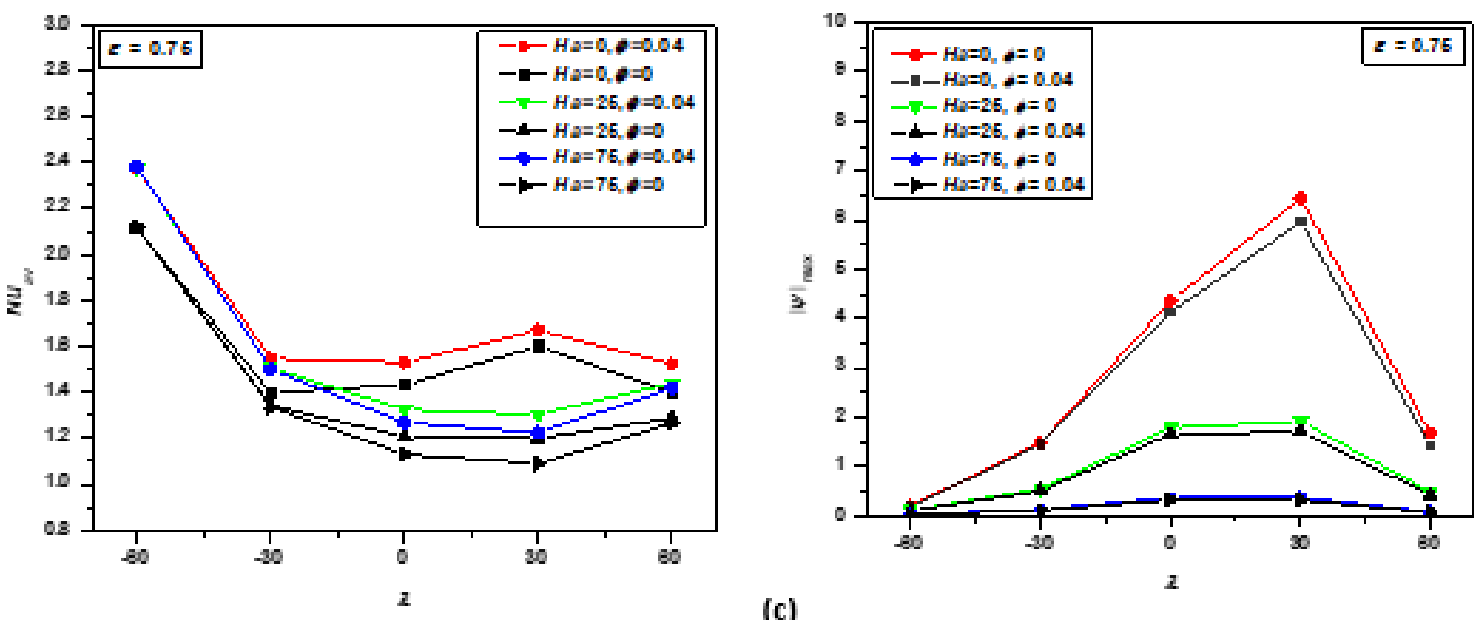

(c)

Fig. 8. Variation of average Nusselt number and absolute max. value of stream function with the inclination angle for both water $(\phi=0)$ and nanofluid $(\phi=0.04)$ at different Hartmann numbers and heat source locations [(a) $\varepsilon=0.25$, (b) $\varepsilon=0.5$ and (c) $\varepsilon=0.75]$ and when [Ra $\left.=10^{4}\right]$ 


\subsubsection{The effect of tilt angles}

The effects of tilt angle on the flow circulation are illustrated in Figure 6 . The flow is observed having great difficulty penetrating the cavity at $(\lambda=-60)$ regardless of Rayleigh number value and heat source position. At such high inclination, the farther the flow intrudes into the cavity, the greater work it must do against buoyancy forces in order to escape. In another words, the cold water which enters from open side is faced by buoyancy force near heat source that prevents to exchange hot water by cold water to form a flow circulation. However, with increasing tilt angle, the effect of the Rayleigh number becomes more pronounced as the flow is better able to enter the cavity and flow strength increase. This can be obviously seen in Figure 7, where the isotherms contours accumulate strongly adjacent the hot left sidewall indicating that the heat is transferred by convection due to the

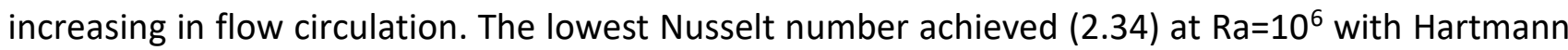
number $(\mathrm{Ha}=0.75)$, angle $\lambda=-60$, heat source position $\varepsilon=0.05$ for pure water. While the maximum Nusselt number reached (6.46) at $\mathrm{Ra}=10^{6}$ with Hartmann number $(\mathrm{Ha}=0)$, angle $\lambda=0$, heat source position $\varepsilon=0.05$, and Nano concentration $(\phi=0.04)$.

At low Rayleigh number numbers (i.e., $\mathrm{Ra}=10^{4}$ ), the flow circulation is weak, and tilt has a minimal affect in increasing the flow strength (Figure 8). This phenomenon is attributed to dominance of the viscous force on the flow circulation compared with the buoyancy force and as described previously the conduction mode is prominent mode. So, the Nusselt number behavior is affected by the heat source position. The lowest Nusselt number achieved (0.98) at Ra=10 ${ }^{4}$ with Hartmann number $(\mathrm{Ha}=0.75)$, angle $\lambda=0$, heat source position $\varepsilon=0.05$ for pure water.

\subsubsection{Relation between Nusselt number and absolute maximum value of stream function}

As mentioned before, the intensity of flow circulation is increased with increase in Rayleigh number which leads to enhancement in heat transfer. Figure 9 and Figure 10 show that the behavior of Nusselt number has the same trend of stream function where the highest value of stream function corresponds to the highest value of Nusselt number and vice versa for $\operatorname{Ra}=10^{5}$ and $10^{6}$. But at $\operatorname{Re}=10^{4}$, there is no compatibility between both of Nusselt number behavior and that of stream function value. This is attributed to the reduction of flow circulation that leading to the dominant of conductive heat transfer. 

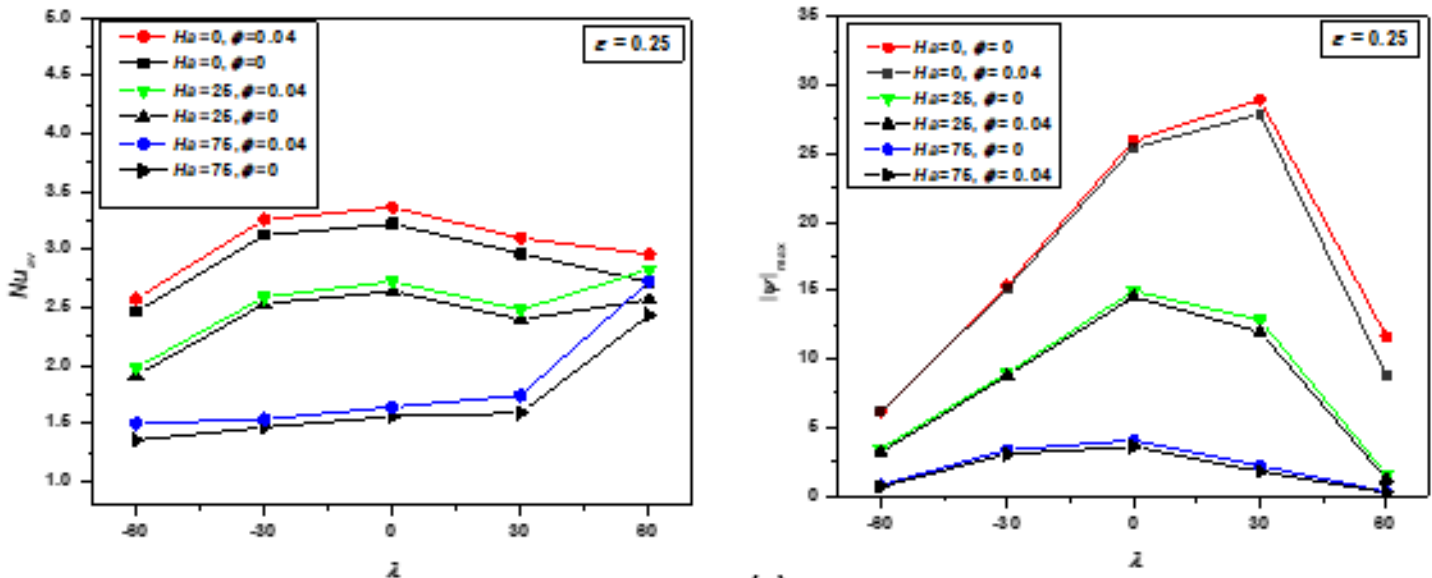

(a)
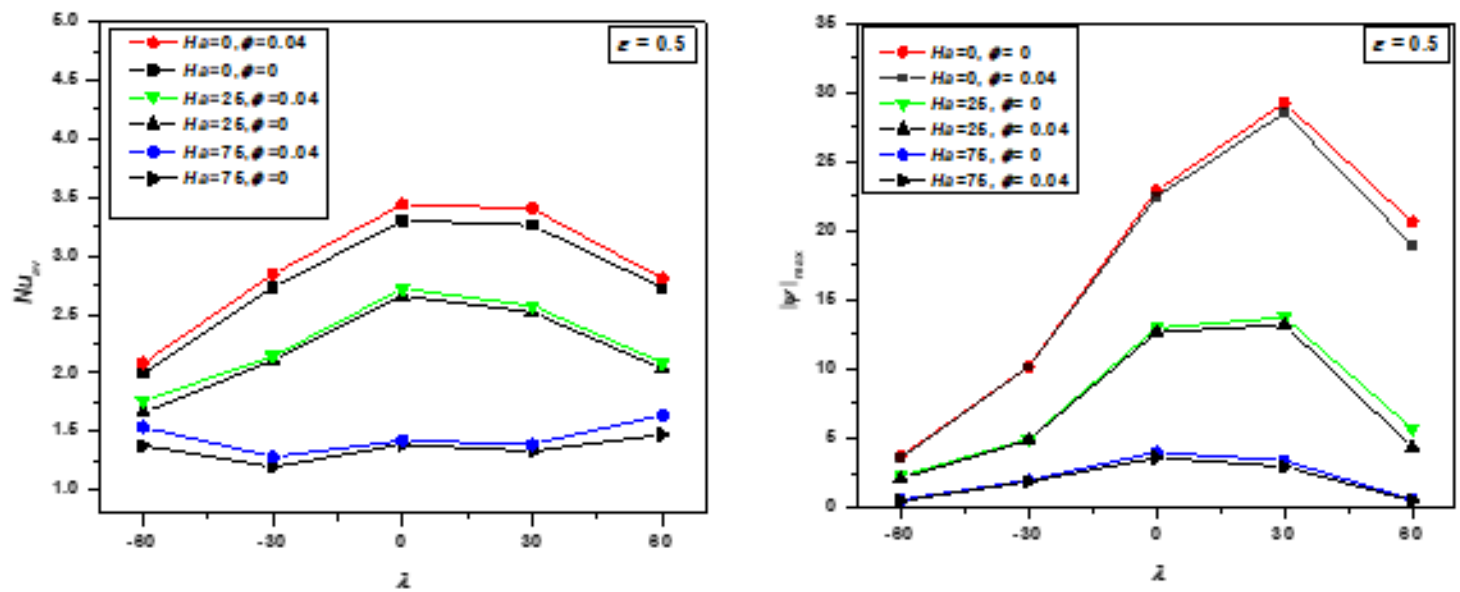

(b)
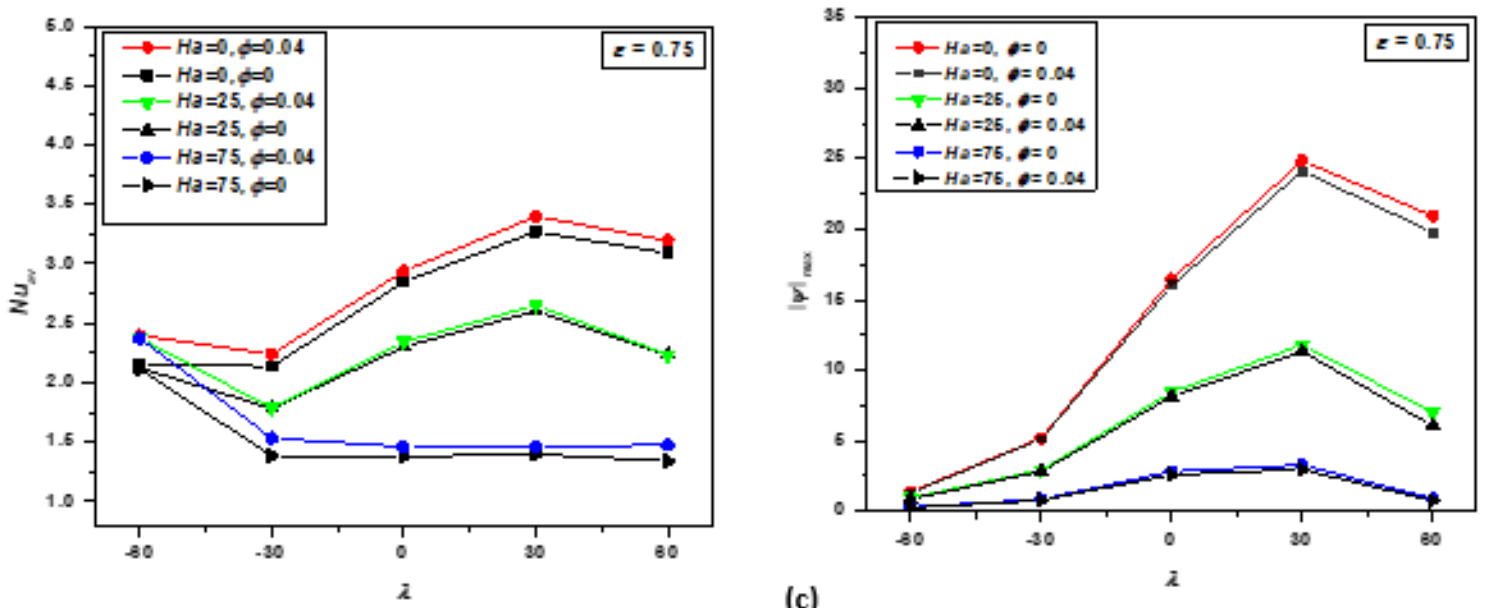

Fig. 9. Variation of average Nusselt number and absolute max. value of stream function with the inclination angle for both water $(\phi=0)$ and nanofluid $(\phi=0.04)$ at different Hartmann numbers and heat source locations [(a) $\varepsilon=0.25$, (b) $\varepsilon=0.5$ and (c) $\varepsilon=0.75]$ and when $\left[\mathrm{Ra}=10^{5}\right]$ 

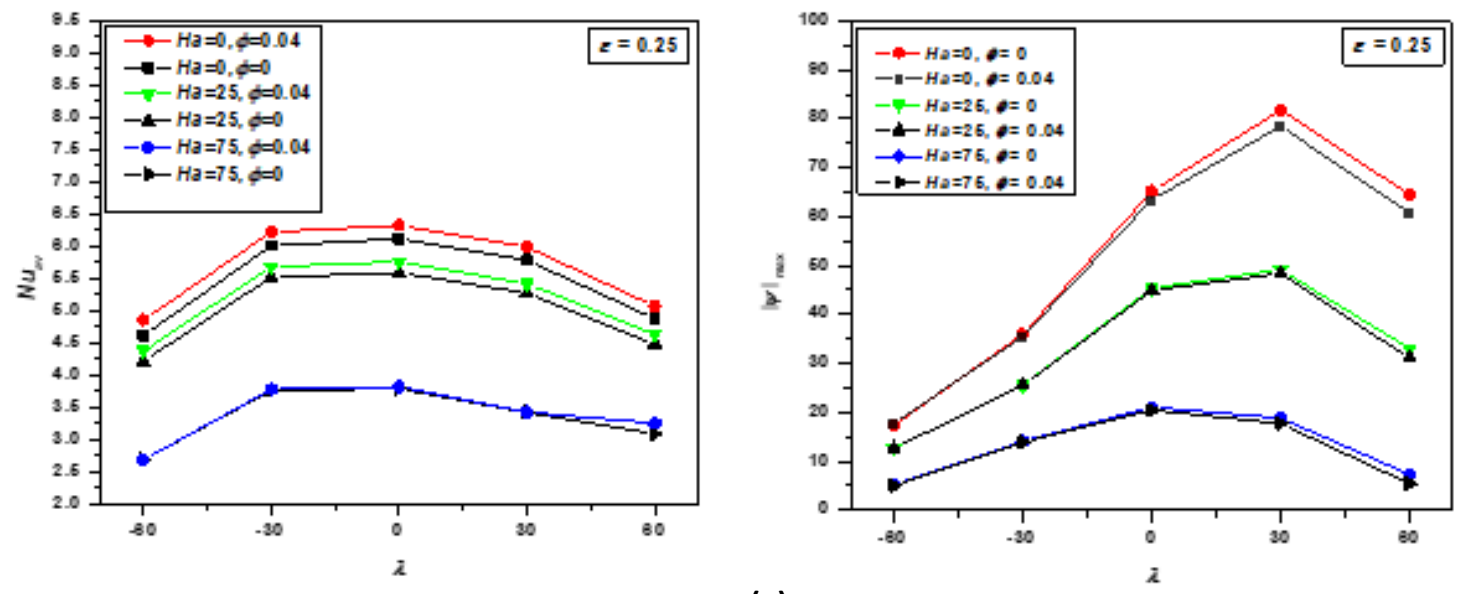

(a)
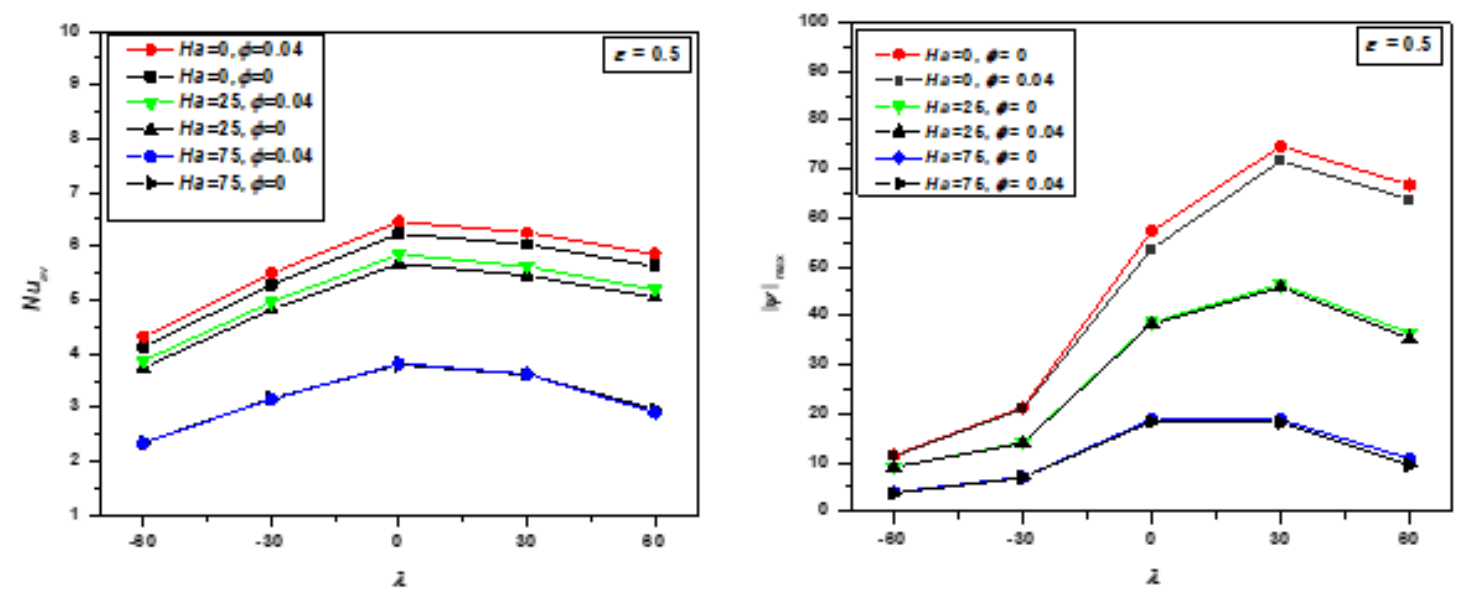

(b)
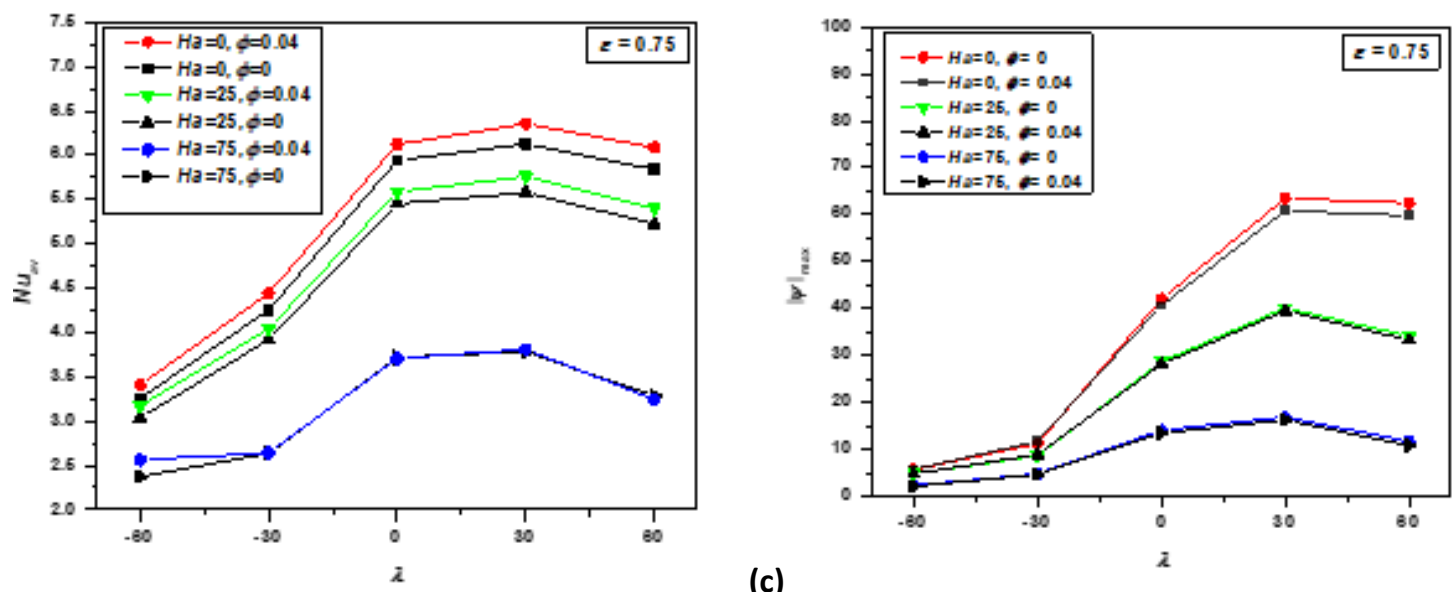

(c)

Fig. 10. Variation of average Nusselt number and absolute max. value of stream function with angle of inclination at $\mathrm{Ra}=106$, for different Hartmann numbers and for pure fluid $(\phi=0)$, and nanofluid ( $\phi=0.04$ ) at heat source positions (a) $\varepsilon=0.25$, (b) $\varepsilon=0.5$, and (c) $\varepsilon=0.75$

\section{Conclusions}

In this study, a numerical investigation of magneto-hydrodynamics (MHD) natural convection flow and heat transfer in a fully opened parallelogrammic enclosure filled with copper-water nanofluid and subjected to a straight magnetic field. Both the upper and lower inclined walls of the 
enclosure are kept cold, while its right sidewall is considered fully opened to the environment. The left sidewall of the enclosure is heated partially, while the remaining parts of it are considered thermally insulated. The results are presented in terms of Nu profiles, and also for the streamline, and isothermal. The predictions included the effects of different values in the dimensionless parameters, specifically, Hartmann number $(0 \leq \mathrm{Ha} \leq 75)$, non-dimensional heat source location $(0.25$ $\leq \varepsilon \leq 0.75)$, Rayleigh number $\left(10^{4} \leq \mathrm{Ra} \leq 10^{6}\right)$ and inclination angles $\left(-60^{\circ} \leq \lambda \leq 60^{\circ}\right)$ on the flow , thermal fields and the average Nusselt number. The results show that

i. The magnetic field results in the Lorentz force causes a severe slowdown in the flow circulation inside the enclosure due to the damping effect. This phenomenon causes a serious deterioration of the heat transfer process for all ranges of Rayleigh numbers, angles of inclination, heat source location and for both types of fluid; nanofluids and water

ii. The Nusselt numbers of nanofluid show more enhancement compared with that of pure water regardless of Rayleigh number, inclination and heat source location. This can be attributed to the higher thermal conductivity of the nanoparticles which leads to increase the transport of the thermal energy inside the enclosure.

iii. The flow is observed having great difficulty penetrating the cavity at $\alpha=-60$ regardless of Rayleigh number value and heat source position. However, with decreasing tilt angle, the effect of the Rayleigh number becomes more pronounced as the flow is better able to enter the cavity and flow strength increase.

iv. For negative inclination angles, the natural convection diminishes when the heat source location increases. While for the highest value of the positive inclination angles [i.e., $\lambda=60^{\circ}$ ], it enhances as the heat source location increases.

v. The lowest Nusselt number achieved (0.98) at $\mathrm{Ra}=10^{4}$ with Hartmann number ( $\left.\mathrm{Ha}=0.75\right)$, angle $\lambda=0$, heat source position $\varepsilon=0.05$ for pure water. While the maximum Nusselt number reached (6.46) at $\mathrm{Ra}=10^{6}$ with Hartmann number $(\mathrm{Ha}=0)$, angle $\lambda=0$, heat source position $\varepsilon=$ 0.05 , and Nano concentration $(\phi=0.04)$

\section{References}

[1] Saha, Sumon, Ahmed Kadhim Hussein, Waqar Ahmed Khan, H. A. Mohammed, Watit Pakdee, and Arman Hasanpour. "Effects of diameter ratio of adiabatic circular cylinder and tilt angle on natural convection from a square open tilted cavity." Heat Transfer-Asian Research 41, no. 5 (2012): 388-401. https://doi.org/10.1002/htj.21001

[2] Hussein, Ahmed Kadhim, S. Kumar Rout, Farshid Fathinia, Ramesh Chand, and H. A. Mohammed. "Natural convection in a triangular top wall enclosure with a solid strip." Journal of Engineering Science and Technology 10, no. 10 (2015): 1326-1341.

[3] Hussain, Salam Hadi, Ahmed Kadhim Hussein, and Mahmoud Moustafa Mahdi. "Natural convection in a square inclined enclosure with vee-corrugated sidewalls subjected to constant flux heating from below." Nonlinear Analysis: Modelling and Control 16, no. 2 (2011): 152-169. https://doi.org/10.15388/NA.16.2.14102

[4] Al-Rashed, Abdullah A. A. A., Lioua Kolsi, Ahmed Kadhim Hussein, Walid Hassen, Mohamed Aichouni, and Mohamed Naceur Borjini. "Numerical Study of Three-Dimensional Natural Convection and Entropy Generation in a Cubical Cavity with Partially Active Vertical Walls." Case Studies in Thermal Engineering 10 (2017): 100-110. https://doi.org/10.1016/i.csite.2017.05.003

[5] Ahmed, Sameh Elsayed, Ahmed Kadhim Hussein, M. M. Abd El-Aziz, and Sivanandam Sivasankaran. "Conjugate natural convection in an inclined square porous enclosure with finite wall thickness and partially heated from its left sidewall." Heat Transfer Research 47, no. 4 (2016). https://doi.org/10.1615/HeatTransRes.2016007964

[6] Penot, F. "Numerical calculation of two-dimensional natural convection in isothermal open cavities." Numerical Heat Transfer, Part A Applications 5, no. 4 (1982): 421-437.

https://doi.org/10.1080/10407788208913457 
[7] Chan, Y. L., and C. L. Tien. "A numerical study of two-dimensional natural convection in square open cavities." Numerical Heat Transfer 8, no. 1 (1985): 65-80. https://doi.org/10.1080/01495728508961842

[8] Chan, Y. L., and C. L. Tien. "A numerical study of two-dimensional laminar natural convection in shallow open cavities." International Journal of Heat and Mass Transfer 28, no. 3 (1985): 603-612. https://doi.org/10.1016/0017-9310(85)90182-6

[9] Miyamoto, M., T. H. Kuehn, R. J. Goldstein, and Y. Katoh. "Two-dimensional laminar natural convection heat transfer from a fully or partially open square cavity." Numerical Heat Transfer 15, no. 4 (1989): 411-430. https://doi.org/10.1080/10407788908944696

[10] Vafai, Kambiz, and Javad Ettefagh. "Thermal and fluid flow instabilities in buoyancy-driven flows in open-ended cavities." International Journal of Heat and Mass Transfer 33, no. 10 (1990): 2329-2344. https://doi.org/10.1016/0017-9310(90)90130-M

[11] Lage, J. L., J. S. Lim, and A. Bejan. "Natural convection with radiation in a cavity with open top end." Journal of Heat Transfer 114, no. 2 (1992): 479-486. https://doi.org/10.1115/1.2911298

[12] Balaji, C., and S. P. Venkateshan. "Interaction of radiation with free convection in an open cavity." International Journal of Heat and Fluid Flow 15, no. 4 (1994): 317-324.

https://doi.org/10.1016/0142-727X(94)90017-5

[13] Khanafer, Khalil, and Kambiz Vafai. "Buoyancy-driven flow and heat transfer in open-ended enclosures: elimination of the extended boundaries." International Journal of Heat and Mass Transfer 43, no. 22 (2000): 4087-4100. https://doi.org/10.1016/S0017-9310(00)00047-8

[14] Khanafer, K., and K. Vafai. "Effective boundary conditions for buoyancy-driven flows and heat transfer in fully openended two-dimensional enclosures." International Journal of Heat and Mass Transfer 45, no. 12 (2002): 2527-2538. https://doi.org/10.1016/S0017-9310(01)00349-0

[15] Singh, S. N., and S. P. Venkateshan. "Numerical study of natural convection with surface radiation in side-vented open cavities." International Journal of Thermal Sciences 43, no. 9 (2004): 865-876. https://doi.org/10.1016/j.ijthermalsci.2004.01.002

[16] Hinojosa, J. F., R. E. Cabanillas, G. Alvarez, and C. E. Estrada. "Nusselt number for the natural convection and surface thermal radiation in a square tilted open cavity." International Communications in Heat and Mass Transfer 32, no. 9 (2005): 1184-1192. https://doi.org/10.1016/j.icheatmasstransfer.2005.05.007

[17] Saha, Goutam, Sumon Saha, and Md Arif Hasan Mamun. "A finite element method for steady-state natural convection in a square tilt open cavity." ARPN Journal of Engineering and Applied Sciences 2, no. 2 (2007): 41-49.

[18] Juárez, José Octavio, Jesús Fernando Hinojosa, Jesús Perfecto Xamán, and Manuel Pérez Tello. "Numerical study of natural convection in an open cavity considering temperature-dependent fluid properties." International Journal of Thermal Sciences 50, no. 11 (2011): 2184-2197. https://doi.org/10.1016/j.ijthermalsci.2011.05.017

[19] Prakash, M., S. B. Kedare, and J. K. Nayak. "Numerical study of natural convection loss from open cavities." International Journal of Thermal Sciences 51 (2012): 23-30. https://doi.org/10.1016/i.ijthermalsci.2011.08.012

[20] Montiel-Gonzalez, M., J. F. Hinojosa, H. I. Villafan-Vidales, A. Bautista-Orozco, and C. A. Estrada. "Theoretical and experimental study of natural convection with surface thermal radiation in a side open cavity." Applied Thermal Engineering 75 (2015): 1176-1186.

https://doi.org/10.1016/j.applthermaleng.2014.05.047

[21] Gangawane, Krunal M., Ram P. Bharti, and Surendra Kumar. "Lattice Boltzmann analysis of natural convection in a partially heated open ended enclosure for different fluids." Journal of the Taiwan Institute of Chemical Engineers 49 (2015): 27-39. https://doi.org/10.1016/i.jtice.2014.11.020

[22] Zamora, Blas, and Germán Sancho. "Effects of heating intensity on the transient natural convection flows in open cavities." International Journal of Heat and Mass Transfer 100 (2016): 861-875. https://doi.org/10.1016/i.ijheatmasstransfer.2016.05.018

[23] Hinojosa, J. F., David Buentello, J. Xamán, and Manuel Pérez-Tello. "The effect of surface thermal radiation on entropy generation in an open cavity with natural convection." International Communications in Heat and Mass Transfer 81 (2017): 164-174. https://doi.org/10.1016/j.icheatmasstransfer.2016.12.018

[24] El-Gendi, Mahmoud M. "Numerical simulation of unsteady natural convection flow inside a pattern of connected open square cavities." International Journal of Thermal Sciences 127 (2018): 373-383. 
https://doi.org/10.1016/j.jithermalsci.2018.02.008

[25] Mezrhab, Ahmed, Samir Amraqui, and Chérifa Abid. "Modelling of combined surface radiation and natural convection in a vented "T" form cavity." International Journal of Heat and Fluid Flow 31, no. 1 (2010): 83-92.

https://doi.org/10.1016/i.ijheatfluidflow.2009.10.004

[26] Wu, Shuang-Ying, Jing-Yu Guan, Lan Xiao, Zu-Guo Shen, and Lian-Hui Xu. "Experimental investigation on heat loss of a fully open cylindrical cavity with different boundary conditions." Experimental Thermal and Fluid Science 45 (2013): 92-101.

https://doi.org/10.1016/i.expthermflusci.2012.10.010

[27] Wu, Shuang-Ying, Feng-Hua Guo, and Lan Xiao. "Numerical investigation on combined natural convection and radiation heat losses in one side open cylindrical cavity with constant heat flux." International Journal of Heat and Mass Transfer 71 (2014): 573-584.

https://doi.org/10.1016/i.ijheatmasstransfer.2013.12.064

[28] Hussein, Ahmed Kadhim. "Computational analysis of natural convection in a parallelogrammic cavity with a hot concentric circular cylinder moving at different vertical locations." International Communications in Heat and Mass Transfer 46 (2013): 126-133.

https://doi.org/10.1016/j.icheatmasstransfer.2013.05.008

[29] Hussain, Salam Hadi, Ahmed Kadhim Hussein, and Kareema Abdul Kadim. "Numerical Simulation of Natural Convection in a Parallelogrammic Enclosure Containing Volumetric Heat Source with Non-uniformly Heated Left Sidewall." Heat Transfer-Asian Research 43, no. 6 (2014): 542-560. https://doi.org/10.1002/htj.21096

[30] Villeneuve, Thierry, Matthieu Boudreau, and Guy Dumas. "The thermal diode and insulating potentials of a vertical stack of parallelogrammic air-filled enclosures." International Journal of Heat and Mass Transfer 108 (2017): 20602071.

https://doi.org/10.1016/i.ijheatmasstransfer.2016.12.067

[31] Yüncü, H., and S. Yamac. "Laminar natural convective heat transfer in an air-filled parallelogramic cavity." International Communications in Heat and Mass Transfer 18, no. 4 (1991): 559-568. https://doi.org/10.1016/0735-1933(91)90069-G

[32] Naylor, D., and P. H. Oosthuizen. "A numerical study of free convective heat transfer in aparallelogram-shaped enclosure." International Journal of Numerical Methods for Heat \& Fluid Flow 4, no. 6 (1994): 553-559. https://doi.org/10.1108/EUM0000000004113

[33] Baïri, A. "Transient free convection in passive buildings using 2D air-filled parallelogram-shaped enclosures with discrete isothermal heat sources." Energy and Buildings 43, no. 2-3 (2011): 366-373. https://doi.org/10.1016/i.enbuild.2010.09.028

[34] Baïri, Abderrahmane, JM García de María, Iken Baïri, Najib Laraqi, Esther Zarco-Pernia, and Nacim Alilat. "2D transient natural convection in diode cavities containing an electronic equipment with discrete active bands under constant heat flux." International Journal of Heat and Mass Transfer 55, no. 19-20 (2012): 4970-4980. https://doi.org/10.1016/j.ijheatmasstransfer.2012.04.032

[35] Villeneuve, Thierry, Matthieu Boudreau, and Guy Dumas. "The thermal diode and insulating potentials of a vertical stack of parallelogrammic air-filled enclosures." International Journal of Heat and Mass Transfer 108 (2017): 20602071. https://doi.org/10.1016/ji.ijheatmasstransfer.2016.12.067

[36] Maatki, Chemseddine, Kaouther Ghachem, Lioua Kolsi, Ahmed Kadhim Hussein, Mohamed Naceur Borjini, and Habib Ben Aissia. "Inclination effects of magnetic field direction in 3D double-diffusive natural convection." Applied Mathematics and Computation 273 (2016): 178-189.

https://doi.org/10.1016/i.amc.2015.09.043

[37] Chand, R., G. C. Rana, and A. K. Hussein. "On the onsetof thermal instability in a low Prandtl number nanofluid layer in a porous medium." Journal of Applied Fluid Mechanics 8, no. 2 (2015): 265-272. https://doi.org/10.18869/acadpub.jafm.67.221.22830

[38] Hussein, Ahmed Kadhim. "Applications of nanotechnology to improve the performance of solar collectors-Recent advances and overview." Renewable and Sustainable Energy Reviews 62 (2016): 767-792. https://doi.org/10.1016/i.rser.2016.04.050

[39] Hussein, Ahmed Kadhim, Dong Li, Lioua Kolsi, Sanatana Kata, and Brundaban Sahoo. "A review of nano fluid role to improve the performance of the heat pipe solar collectors." Energy Procedia 109 (2017): 417-424. https://doi.org/10.1016/i.egypro.2017.03.044

[40] Kolsi, Lioua, Abdullah A. A. A. Alrashed, Khaled Al-Salem, Hakan F. Oztop, and Mohamed Naceur Borjini. "Control of natural convection via inclined plate of CNT-water nanofluid in an open sided cubical enclosure under magnetic field." International Journal of Heat and Mass Transfer 111 (2017): 1007-1018. 
https://doi.org/10.1016/j.ijheatmasstransfer.2017.04.069

[41] Hussein, Ahmed Kadhim, Hamid Reza Ashorynejad, Mohsen Shikholeslami, and S. Sivasankaran. "Lattice Boltzmann simulation of natural convection heat transfer in an open enclosure filled with Cu-water nanofluid in a presence of magnetic field." Nuclear Engineering and Design 268 (2014): 10-17.

https://doi.org/10.1016/i.nucengdes.2013.11.072

[42] Hussein, Ahmed Kadhim, M. A. Y. Bakier, Mohamed Bechir Ben Hamida, and S. Sivasankaran. "Magnetohydrodynamic natural convection in an inclined T-shaped enclosure for different nanofluids and subjected to a uniform heat source." Alexandria Engineering Journal 55, no. 3 (2016): 2157-2169.

https://doi.org/10.1016/i.aej.2016.06.020

[43] Kefayati, GH R. "Effect of a magnetic field on natural convection in an open cavity subjugated to water/alumina nanofluid using Lattice Boltzmann method." International Communications in Heat and Mass Transfer 40 (2013): 67-77.

https://doi.org/10.1016/j.icheatmasstransfer.2012.10.024

[44] Mejri, Imen, and Ahmed Mahmoudi. "MHD natural convection in a nanofluid-filled open enclosure with a sinusoidal boundary condition." Chemical Engineering Research and Design 98 (2015): 1-16.

https://doi.org/10.1016/j.cherd.2015.03.028

[45] Gangawane, Krunal M. "Effect of angle of applied magnetic field on natural convection in an open ended cavity with partially active walls." Chemical Engineering Research and Design 127 (2017): 22-34. https://doi.org/10.1016/i.cherd.2017.09.006

[46] Bakier, M. A. Y. "Flow in open C-shaped cavities: How far does the change in boundaries affect nanofluid?." Engineering Science and Technology, an International Journal 17, no. 3 (2014): 116-130.

https://doi.org/10.1016/i.jestch.2014.04.007

[47] Miroshnichenko, Igor V., Mikhail A. Sheremet, Hakan F. Oztop, and Khaled Al-Salem. "MHD natural convection in a partially open trapezoidal cavity filled with a nanofluid." International Journal of Mechanical Sciences 119 (2016): 294-302.

https://doi.org/10.1016/i.ijmecsci.2016.11.001

[48] Ashorynejad, Hamid Reza, and Alireza Shahriari. "MHD natural convection of hybrid nanofluid in an open wavy cavity." Results in Physics 9 (2018): 440-455.

https://doi.org/10.1016/j.rinp.2018.02.045

[49] Astanina, Marina S., Mikhail A. Sheremet, Hakan F. Oztop, and Nidal Abu-Hamdeh. "MHD natural convection and entropy generation of ferrofluid in an open trapezoidal cavity partially filled with a porous medium." International Journal of Mechanical Sciences 136 (2018): 493-502.

https://doi.org/10.1016/i.ijmecsci.2018.01.001

[50] Bahiraei, Mehdi, Nima Mazaheri, and Seyed Mohammadhossein Hassanzamani. "Efficacy of a new grapheneplatinum nanofluid in tubes fitted with single and twin twisted tapes regarding counter and co-swirling flows for efficient use of energy." International Journal of Mechanical Sciences 150 (2019): 290-303.

https://doi.org/10.1016/j.ijmecsci.2018.10.036

[51] Bahiraei, Mehdi, Nima Mazaheri, and Faegheh Aliee. "Second law analysis of a hybrid nanofluid in tubes equipped with double twisted tape inserts." Powder Technology 345 (2019): 692-703.

https://doi.org/10.1016/i.powtec.2019.01.060

[52] Adnan, Nurul Shahirah Mohd, Norihan Md Arifin, Norfifah Bachok, and Fadzilah Md Ali. "Stability Analysis of MHD Flow and Heat Transfer Passing A Permeable Exponentially Shrinking Sheet with Partial Slip and Thermal Radiation." CFD Letters 11, no. 12 (2019): 34-42.

[53] Bahiraei, Mehdi, Mohammad Jamshidmofid, and Marjan Goodarzi. "Efficacy of a hybrid nanofluid in a new microchannel heat sink equipped with both secondary channels and ribs." Journal of Molecular Liquids 273 (2019): 88-98.

https://doi.org/10.1016/j.molliq.2018.10.003

[54] Bahiraei, Mehdi, Nima Mazaheri, Mehran Sheykh Mohammadi, and Hossein Moayedi. "Thermal performance of a new nanofluid containing biologically functionalized graphene nanoplatelets inside tubes equipped with rotating coaxial double-twisted tapes." International Communications in Heat and Mass Transfer 108 (2019): 104305.

https://doi.org/10.1016/i.icheatmasstransfer.2019.104305

[55] Hussein, Ahmed Kadhim, and Ahmed Waheed Mustafa. "Natural convection in fully open parallelogrammic cavity filled with Cu-water nanofluid and heated locally from its bottom wall." Thermal Science and Engineering Progress 1 (2017): 66-77.

https://doi.org/10.1016/i.tsep.2017.03.002 
[56] Teamah, Mohamed A., and Wael M. El-Maghlany. "Augmentation of natural convective heat transfer in square cavity by utilizing nanofluids in the presence of magnetic field and uniform heat generation/absorption." International Journal of Thermal Sciences 58 (2012): 130-142.

https://doi.org/10.1016/j.ijthermalsci.2012.02.029

[57] Hadi Hussain, Salam, and Ahmed Kadhim Hussein. "Natural convection heat transfer enhancement in a differentially heated parallelogrammic enclosure filled with copper-water nanofluid." Journal of Heat Transfer 136, no. 8 (2014).

https://doi.org/10.1115/1.4027448

[58] Hussein, Ahmed Kadhim, Kolsi Lioua, Ramesh Chand, S. Sivasankaran, Rasoul Nikbakhti, Dong Li, Borjini Mohamed Naceur, and Ben Aïssia Habib. "Three-dimensional unsteady natural convection and entropy generation in an inclined cubical trapezoidal cavity with an isothermal bottom wall." Alexandria Engineering Journal 55, no. 2 (2016): 741-755. https://doi.org/10.1016/j.aej.2016.01.004

[59] Barth, Timothy, and Mario Ohlberger. "Finite Volume Methods: Foundation and Analysis." Encyclopedia of Computational Mechanics, 2004. https://doi.org/10.1002/0470091355.ecm010

[60] Ghasemi, B., S. M. Aminossadati, and A. Raisi. "Magnetic field effect on natural convection in a nanofluid-filled square enclosure." International Journal of Thermal Sciences 50, no. 9 (2011): 1748-1756. https://doi.org/10.1016/i.ijthermalsci.2011.04.010

[61] Said, Mazuriah, Shabudin B. Mat, Shuhaimi Mansor, Ainullotfi Abdul-Latif, and Tholudin Mat Lazim. "Reynolds Number Effects on Flow Topology Above Blunt-edged Delta Wing VFE-2 Configurations." In 53rd AIAA Aerospace Sciences Meeting, p. 1229. 2015. https://doi.org/10.2514/6.2015-1229

[62] Luckring, James M. "Initial experiments and analysis of blunt-edge vortex flows for VFE-2 configurations at NASA Langley, USA." Aerospace Science and Technology 24, no. 1 (2013): 10-21. https://doi.org/10.1016/i.ast.2012.02.005

[63] Konrath, Robert, Christian Klein, and Andreas Schröder. "PSP and PIV investigations on the VFE-2 configuration in sub-and transonic flow." Aerospace Science and Technology 24, no. 1 (2013): 22-31. https://doi.org/10.1016/j.ast.2012.09.003

[64] Fritz, Willy. "Numerical simulation of the peculiar subsonic flow-field about the VFE-2 delta wing with rounded leading edge." Aerospace Science and Technology 24, no. 1 (2013): 45-55. https://doi.org/10.1016/j.ast.2012.02.006

[65] Chu, Julio, and James M. Luckring. Experimental surface pressure data obtained on 65 delta wing across Reynolds number and Mach number ranges. National Aeronautics and Space Administration, Langley Research Center, 1996. 